\title{
Assessing the Performance of Environmentally Friendly-Produced Zerovalent Iron Nanoparticles to Remove Pharmaceuticals from Water
}

\author{
Iliana Panagou ${ }^{1, *}$, Constantinos Noutsopoulos ${ }^{1}\left(\mathbb{D}\right.$, Christiana Mystrioti $^{2}$, Evridiki Barka ${ }^{1} \mathbb{D}$, Elena Koumaki ${ }^{1}$, \\ Maria Kalli ${ }^{1}{ }^{\mathbb{D}}$, Simos Malamis ${ }^{1}$, Nymphodora Papassiopi ${ }^{2}$ and Daniel Mamais ${ }^{1}$
}

1 Sanitary Engineering Laboratory, Department of Water Resources and Environmental Engineering, School of Civil Engineering, National Technical University of Athens, 15780 Athens, Greece; cnoutso@central.ntua.gr (C.N.); ebarka8@gmail.com (E.B.); elenakoumaki@gmail.com (E.K.); mariax24k@gmail.com (M.K.); malamis.simos@gmail.com (S.M.); mamais@central.ntua.gr (D.M.)

2 School of Mining and Metallurgical Engineering, National Technical University of Athens, 15780 Athens, Greece; chmistrioti@metal.ntua.gr (C.M.); papasiop@metal.ntua.gr (N.P.)

* Correspondence: iliana.panagou@central.ntua.gr

Citation: Panagou, I.;

Noutsopoulos, C.; Mystrioti, C.;

Barka, E.; Koumaki, E.; Kalli, M.;

Malamis, S.; Papassiopi, N.;

Mamais, D. Assessing the

Performance of Environmentally

Friendly-Produced Zerovalent Iron

Nanoparticles to Remove

Pharmaceuticals from Water.

Sustainability 2021, 13, 12708.

https://doi.org/10.3390/su132212708

\section{Academic Editors: Anna}

Laura Eusebi, Nicola Frison and

Çağrı Akyol

Received: 15 October 2021

Accepted: 15 November 2021

Published: 17 November 2021

Publisher's Note: MDPI stays neutral with regard to jurisdictional claims in published maps and institutional affiliations.

Copyright: (c) 2021 by the authors. Licensee MDPI, Basel, Switzerland. This article is an open access article distributed under the terms and conditions of the Creative Commons Attribution (CC BY) license (https:/ / creativecommons.org/licenses/by/ $4.0 /)$.
Abstract: Nano zerovalent iron (nZVI), produced from green tea extracts, was incorporated in a cation exchange resin ( $\mathrm{R}-\mathrm{nFe}$ ) to investigate its performance regarding the removal of four nonsteroidal anti-inflammatory drugs (NSAIDs): ibuprofen (IBU), naproxen (NPX), ketoprofen (KTP) and diclofenac (DCF). The effect of contact time, $\mathrm{NaCl}$ pretreatment, $\mathrm{pH}, \mathrm{R}-\mathrm{nFe}$ dose, the role of the supporting material, the initial concentration of pollutants, and the combined effect of nZVI with oxidative reagents was assessed through a series of batch experiments. According to the results, the best removal efficiencies obtained for DCF and KTP were $86 \%$ and $73 \%$, respectively, at $48 \mathrm{~h}$ of contact time with $\mathrm{NaCl}$ pretreated $\mathrm{R}-\mathrm{nFe}$ at a dose of $15 \mathrm{~g} \mathrm{~L}^{-1}$ and a $\mathrm{pH}$ of 4 . The maximum removal efficiency for NPX was 90\% for a contact time of $60 \mathrm{~min}$ with PS $1 \mathrm{mM}$ and a pH of 3, which was quite similar to the experiment with a greater contact time of $48 \mathrm{~h}$ without PS addition. The maximum IBU removal was $70 \%$; this was reached at $\mathrm{pH} 3$, with a contact time of $30 \mathrm{~min}$ and $\mathrm{R}-\mathrm{nFe} 15 \mathrm{~g} \mathrm{~L}^{-1}$. To the authors' best knowledge, this is the first study investigating the utilization of nZVI, produced from leaf extracts and incorporated into a cationic exchange resin, to remove NSAIDs from water.

Keywords: non-steroidal anti-inflammatory drugs (NSAIDs); contaminants of emerging concern; nano zerovalent iron; green synthesis method; green tea extracts; Fenton process

\section{Introduction}

The occurrence of recalcitrant and persistent micropollutants in the environment is nowadays of major concern for the preservation of the quality of natural resources and the protection of biodiversity and human health. These micropollutants are usually referred to in the literature as "emerging contaminants" (ECs), "emerging pollutants" (EPs) or "contaminants of emerging concern" (CECs); they include a wide range of chemicals that are contained in everyday products, such as pharmaceuticals and personal care products (PPCPs), pesticides, plasticizers, illicit drugs, and others [1,2]. The main reasons for the rising concern around these substances are their increasing detection globally in receiving waters $[3,4]$, the uncertainty about the mechanisms they can interact with, and their fate in the environment [5], along with the fact that many of these substances have been proven to have adverse effects on aquatic life and human health, even when present at trace concentration levels ( $\mathrm{ng} \mathrm{L}^{-1}-\mu \mathrm{g} \mathrm{L}^{-1}$ ) [6]. It has been reported that they may affect the reproductive system of aquatic organisms and cause kidney alterations and carcinogenesis; they are also suspected of causing genetic modifications in humans [7-10]. Among the CECs, non-steroidal anti-inflammatory drugs (NSAIDs) are a vast category of chemical compounds that are used worldwide to treat inflammation, fever, and pain [11-13]. 
NSAIDs enter the environment from discrete and dispersed sources, but their entrance into water bodies occurs primarily via the discharge points of wastewater treatment plants (WWTPs) treating the municipal, hospital or pharmaceutical industry's wastewater $[6,7,14]$. Their extensive consumption, along with the limited capacity of conventional WWTPs to effectively remove these emerging contaminants from wastewater $[1,15,16]$, results in their frequent occurrence in the aquatic environment. Moreover, the expected increase in population in the coming decades creates additional pressure to find adequate, cost-effective treatment technologies for the production of reclaimed water that is free of chemicals.

During the last few decades, several methods have been investigated for removing NSAIDs from water, including adsorption techniques like activated carbon [14], electrocoagulation [17], advanced oxidation processes [18,19], ozonation [20], sonolysis [21] and other methods [22,23]. Nano zerovalent iron (nZVI) has been recently employed for the removal of a wide range of complex chemical compounds, such as trichloroethylenes (TCEs) [24,25], biphenyls [26], heavy metals [1,2,27], pesticides [3], dyes [28] and other pollutants. Its unique structure enables nZVI to react through various mechanisms (including adsorption, oxidation, precipitation and reduction) with the targeted pollutants to enable their elimination $[29,30]$. nZVI particles consist of a $\mathrm{Fe}^{0}$ core that is surrounded by a layer of iron oxides/hydroxides [31-33]. The thickness of the surrounding layer increases as the core is oxidized [28,31]. Recently, nZVI performance has also been investigated in lab experiments for the removal of various CECs, including endocrine-disrupting chemicals $[34,35]$ and antibiotics [36-38], since nZVI can be employed as a source of $\mathrm{Fe}^{+3} / \mathrm{Fe}^{+2}$ for initiating Fenton and Fenton-like reactions in the presence of oxidative reagents.

The main advantages of nZVI are that nanoparticles have a small particle size and large specific area that maximize the available sites for reacting with target pollutants, with which they are highly reactive, thus promoting mass transfer $[39,40]$. Furthermore, nZVI can be synthesized via an environmentally friendly method utilizing leaf and tree extracts. Leaf extracts contain polyphenols that are capable of reducing the trivalent iron $\mathrm{Fe}^{+3}$ to $\mathrm{Fe}^{0}$ [41]. The majority of previous studies [35,42-46] evaluated the performance of nZVI when synthesized by the chemical reduction of iron ions using $\mathrm{NaBH}_{4}$ as a reducing agent, a costly reagent that also generates unsafe byproducts (e.g., hydrogen gas). Instead, the application of a green synthesis route for the production of nZVI particles may offer a more cost-efficient and environmentally friendly option for water treatment. Garden waste and various tree leaves can be valorized and used as polyphenol sources for the synthesis of nZVI particles. Machado et al. [47] used extracts from natural products, such as black tea leaves, grape marc, and vine leaves, in order to substitute sodium borohydride for the reduction of ferric iron to elemental iron. The extraction of polyphenols from agricultural waste is a sustainable method that can lead to high-value products, such as (i) individual pharmaceutical-grade polyphenols isolated from the complex extract by applying novel separation techniques [48], or (ii) nanomaterials synthesized by exploiting the antioxidant potential of extracted polyphenols $[47,49]$. The recycling and transformation of agricultural waste into addedvalue materials can significantly reduce the carbon footprint and environmental factors, and promote economic sustainability $[48,50]$.

However, nanoparticles have a tendency to agglomerate [51,52], thus decreasing the beneficial effects of their size and reducing the active sites for reactions. Another problem related to the use of nZVI is the ultimate fate of those nanoparticles in the case of accidental release into the natural environment [53]. There is growing concern that nanomaterials may have serious toxic effects on several species of the aquatic and terrestrial biota. Ecotoxic effects have been reported for a wide range of engineered nanoparticles, including $\mathrm{Ag}$, $\mathrm{ZnO}, \mathrm{TiO}_{2}$ nanoparticles, carbon nanotubes, etc. [54]. Research about the ecotoxicity of iron nanoparticles is not yet conclusive [55]; however, concerns still remain and, for this reason, the direct injection of nZVI suspensions in contaminated aquifers, which appeared as a highly promising remediation technology in the early 2000s, had few large-scale applications during the last few years. 
An alternative option for taking advantage of the high reactivity of nZVI and avoiding the spread of nanoparticles in the natural environment is the incorporation and fixation of nZVI in a porous matrix. Porous materials which have been used as host matrices for nZVI fixation include biochar [56], carbon nanotubes [57], zeolites [58], ion exchange resins [59], etc. In addition, supporting materials may also increase active sites for reactions with the targeted pollutants, thus having a binary beneficial effect.

In view of the above, a novel, environmentally friendly method has been employed in the present study in order to assess the performance of nZVI in terms of the removal of targeted pharmaceutical compounds from water. More specifically, nZVI produced with green tea (GT) extracts have been incorporated in a cationic exchange resin to investigate its removal efficiency regarding four NSAIDs, these being ibuprofen (IBU), diclofenac (DCF), ketoprofen (KTP) and naproxen (NPX) in batch tests.

The properties and chemical structure of the selected NSAIDs are presented in Table 1 . The effect of contact time, $\mathrm{NaCl}$ pretreatment, $\mathrm{pH}$, supporting material, the target compound's initial concentration, the dose of the resin incorporating nZVI made with green tea extracts (denoted hereafter as $\mathrm{R}-\mathrm{nFe}$ ), and the addition of oxidative reagents were investigated.

Table 1. Chemical structure and properties of the four selected NSAIDs.

\begin{tabular}{|c|c|c|c|c|c|c|}
\hline $\begin{array}{l}\text { Chemical } \\
\text { Compound }\end{array}$ & Chemical Type & $\begin{array}{l}\text { Chemical } \\
\text { Structure }\end{array}$ & $\begin{array}{c}\text { Molecular } \\
\text { Weight }(\mathrm{g} / \mathrm{mol})\end{array}$ & LogKow & $\begin{array}{l}\text { Water Solubility } \\
\left(\mathrm{mg} \mathrm{L}^{-1} \mathrm{AT} 20^{\circ} \mathrm{C}\right)\end{array}$ & pKa \\
\hline IBU [60] & $\mathrm{C}_{13} \mathrm{H}_{18} \mathrm{O}_{2}$ & & 206.28 & 3.91 & 21 & 4.59 \\
\hline DCF [61] & $\mathrm{C}_{14} \mathrm{H}_{10} \mathrm{Cl}_{2} \mathrm{NO}_{2} \cdot \mathrm{Na}$ & & 318.13 & 4.51 & 24 & 4.14 \\
\hline KTP [62] & $\mathrm{C}_{16} \mathrm{H}_{14} \mathrm{O}_{3}$ & & 254.28 & 3.12 & 51 & 4.45 \\
\hline NPX [63] & $\mathrm{C}_{14} \mathrm{H}_{14} \mathrm{O}_{3}$ & & 230.26 & 3.18 & 16 & 4.15 \\
\hline
\end{tabular}

2. Materials and Methods

\subsection{Materials}

IBU, NPX, KTP and DCF of a high purity grade ( $\geq 93 \%)$ were purchased from Sigma Aldrich (Steinheim, Germany). MCF (Meclofenamic acid sodium salt), was also purchased from Sigma Aldrich (Steinheim, Germany). Methanol (MeOH) and ethyl acetate (ETH) of high-performance liquid chromatography (HPLC) grade were purchased from Merck, and from Fluka, Neu-Ulm, Germany, respectively. Pyridine and bis(trimethylsilyl)trifluoroacetamide (BSTFA) $+1 \%$ trimethylchlorosilane (TMCS) for silylation were purchased from Sigma Aldrich (Steinheim, Germany). Stock solutions of a high concentration (1000 ppm) were prepared for each targeted NSAID. The solutions were stored at $-18{ }^{\circ} \mathrm{C}$, as found in [64]. Cartridges of $\mathrm{C} 186 \mathrm{~mL}$ for solid-phase extraction (SPE) were purchased from Isolute, Biotage. Ultrapure water was prepared in the laboratory using a MilliQ/Milli-RO Millipore system (Millipore, Billerica, MA, USA). Ultra-pure $\mathrm{HCl}(32 \%)$ was used for acidification of the samples (Sigma Aldrich, Steinheim, Germany). Sodium carbonate $\left(\mathrm{Na}_{2} \mathrm{CO}_{3}\right)$ was purchased from Merck, Darmstadt, Germany, and sodium chloride $(\mathrm{NaCl})$, iron chloride hexahydrate $\left(\mathrm{FeCl}_{3} 6 \mathrm{H}_{2} \mathrm{O}\right)$ was purchased from Fluka, Ronkonkoma, NY, USA. The resin, Amberlyst 15 hydrogen form $\left(\mathrm{H}^{+}\right)$wet, was purchased from Sigma Aldrich (Steinheim, Germany). For the green tea extracts, a commercial 
product was used from Twinings of London. Hydrogen peroxide solution $\left(\mathrm{H}_{2} \mathrm{O}_{2}\right), 30 \%$ $(w / w)$ and sodium persulfate $\left(\mathrm{Na}_{2} \mathrm{~S}_{2} \mathrm{O}_{8}\right)$ of high reagent grade $(>98 \%)$ were purchased from Honeywell and Sigma Aldrich (Steinheim, Germany).

\subsection{Analytical Methods}

To quantify the substances, the analytical method developed by Samaras et al. [65] was followed. This method includes pre-concentration of the acidified liquid samples ( $\mathrm{pH} 2.5)$ to ETH solutions of $6 \mathrm{~mL}$ through SPE, the evaporation to dryness of the ETH solutions by nitrogen purge, and the addition of $50 \mu \mathrm{L}$ BSTFA $+1 \%$ TMCS, along with $10 \mu \mathrm{L}$ of pyridine, for derivatization of the targeted compounds in a bath device at $70{ }^{\circ} \mathrm{C}$ for $20 \mathrm{~min}$. The analyses were performed via an Agilent gas chromatograph (7890A) connected with an Agilent mass selective detector (MSD) (5975C). MCF was used as a surrogate for the selected NSAIDs. Water characteristics were determined according to standard methods [66].

\section{3. $R$-nFe Synthesis}

The methodology proposed by Toli et al. [49] for the synthesis of nZVI resin was followed. The main steps of the synthesis procedure are presented in Figure 1. Synoptically, the beads of the resin were treated for $2 \mathrm{~h}$ with $\mathrm{NaCl} 1 \mathrm{M}$ solution at $200 \mathrm{rpm}$ (denoted hereafter as R-Na). Then, the R-Na was agitated at $200 \mathrm{rpm}$ for $4 \mathrm{~h}$ with $\mathrm{FeCl}_{3} 6 \mathrm{H}_{2} \mathrm{O}$ solution at $0.05 \mathrm{M}$ concentration, to allow the sodium ions $\left(\mathrm{Na}^{+}\right)$to be replaced by trivalent iron cations $\left(\mathrm{Fe}^{+3}\right)$. Finally, the R-Fe was agitated for $20 \mathrm{~h}$ with the green tea extracts, to allow the contained polyphenols to reduce the adsorbed $\mathrm{Fe}^{+3}$ to nZVI. Then, the resin containing the nZVI (denoted hereafter as R-nFe) was ready for use.

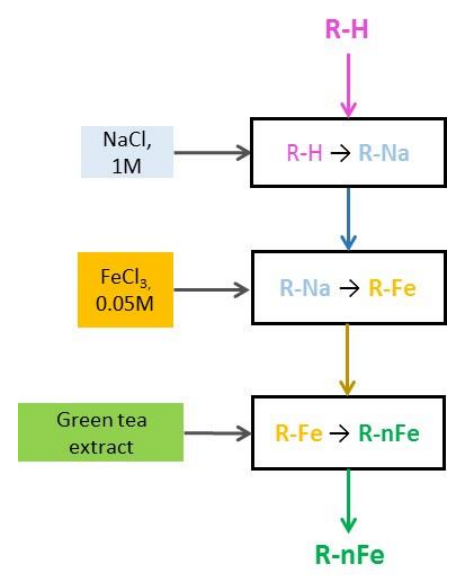

Figure 1. The main steps of R-nFe synthesis procedure.

With the applied synthesis procedure, the total amount of incorporated iron per gram of R-nFe was equal to $0.49 \pm 0.01 \mathrm{mmol} / \mathrm{g}$. Previous studies had indicated that the embedded Fe was amorphous $[49,67]$. To be specific, the X-ray patterns of similar $\mathrm{R}-\mathrm{nFe}$ products did not contain either the characteristic peaks of elemental iron, $\mathrm{Fe}^{0}$, or any detectable peaks of $\mathrm{Fe}^{+3}$ or $\mathrm{Fe}^{+2}$ oxides. For this reason, and in order to estimate the valence state and the content of reduced Fe inside the resin beads after treatment with GT polyphenols, the following procedure was applied. The R-nFe beads were mixed with an aqueous solution containing a stoichiometric excess of $\mathrm{Cr}^{+6}$ with respect to the $\mathrm{Fe}$ in the resin, i.e., the molar ratio of $\mathrm{Cr}^{+6} / \mathrm{nFe}$ in the mixture was equal to 3 . The mixture was agitated for $24 \mathrm{~h}$ at room temperature, then filtrated, and the aqueous phase was analyzed for residual $\mathrm{Cr}^{+6}$. Similar experiments were carried out as control tests, mixing samples of $\mathrm{R}-\mathrm{Fe}$ (prior to GT treatment) and R-Na resin with the same $\mathrm{Cr}^{+6}$ solution. The morphology of resin beads was studied using a scanning electron microscope (SEM), JEOL6380LV. The elemental microanalysis of observed surfaces was carried out via an energy-dispersive system (EDS). The resin samples were prepared by incorporating them in a cylindrical 
epoxy matrix that was cut and abraded to obtain a cut section of the incorporated resin beads. Additional images of R-nFe at the nanoscale were also obtained by transmission electron microscopy (TEM) using a JEOL 2100 HR machine. The R-nFe samples, which had been incorporated in the epoxy matrix, were micro-sectioned using a Leica EM UCT ultramicrotome equipped with a diamond knife. Finally, the resulting fine slices were placed on a grid and were observed at $200 \mathrm{kV}$.

\subsection{Batch Experiments}

All experiments were performed in triplicate using 1 L conical glass flasks, where the targeted compounds were spiked into ultrapure water at an initial concentration of $1 \mu \mathrm{g} \mathrm{L}^{-1}$. The initial concentrations used were selected as indicative values, being in the range of concentrations reported for NSAIDs worldwide in treated wastewater $\left(<0.001-4239 \mu \mathrm{g} \mathrm{L}^{-1}\right)[7,68,69]$. Ultrapure water was agitated with a mixture comprising the targeted compounds in the flask for 15 min to ensure the homogeneity of the solution. After this step, the batch experiments were performed in $1 \mathrm{~L}$ glass bottles, adding the desired R-nFe dose. During the experiments, the bottles were protected against sunlight, and they were placed in an agitation plate adjusted to $200 \mathrm{rpm}$. Liquid samples were collected from the supernatant at regular intervals and the $\mathrm{pH}, \mathrm{T}$, and DO were measured. The samples were then analyzed according to the aforementioned analytical protocol used by Samaras et al. [65].

To investigate the effect of $\mathrm{NaCl}$ pre-treatment, the $\mathrm{R}-\mathrm{nFe}$ was added to the $\mathrm{NaCl}$ $1 \mathrm{M}$ solution for 1 day at an agitation speed of $200 \mathrm{rpm}$, before being utilized in the experiments. In addition, in order to evaluate the $\mathrm{pH}$ effect, the following procedure was applied: (i) acidic conditions $(\mathrm{pH}=3)$ were achieved by adding drops of $\mathrm{HCl} 1 \mathrm{~N}$ solution, whereas (ii) neutral conditions $(\mathrm{pH}=7)$ were established by the addition of $\mathrm{NaHCO}_{3}$. More specifically, the initial $\mathrm{pH}$ adjustment was implemented through the addition of $\mathrm{NaHCO}_{3}$ to the solution at a concentration of $1.5 \mathrm{~g} \mathrm{~L}^{-1}$, to increase the $\mathrm{pH}$ value (the resin, the $\mathrm{nZVI}$, and the green tea extracts utilized for their production have a slightly acidic nature). In the experiments examining the role of the resin, the synthesis methodology for incorporating nZVI was not followed; instead, the resin was used alone, adopting only pre-treatment with $\mathrm{NaCl}$, for comparison with pre-treated R-nFe. Finally, for the experiments investigating the synergistic effect of oxidative agents with nZVI, $\mathrm{H}_{2} \mathrm{O}_{2}$ or PS were added at the beginning of the experiments, along with the R-nFe.

Prior to the above experiments, control experiments were also performed to ensure that the targeted compounds remained stable without the addition of R-nFe. In addition, background tests with R-nFe and ultrapure water were conducted without spiking the compounds. The results indicated that the resin with incorporated nZVI did not have a negative effect on the efficiency of the removal of NPX, DCF, IBU, and KTP.

\section{Results}

\subsection{Characterization of $n Z V I$ Material}

To investigate the valence state of the Fe inside the resin beads, following treatment with the GT polyphenols, representative samples of the resin corresponding to the 3 steps of the synthesis procedure, i.e., R-Na, R-Fe and R-nFe samples, were mixed with an aqueous solution containing a molar excess of $\mathrm{Cr}^{+3}$. The results are presented in Figure 2. Based on these, the amount of $\mathrm{Cr}^{+6}$ removed from the aqueous solution was close to $0.07 \mathrm{mmole}$ per gram of resin, when the solution was mixed with the resin products after the first and second steps of the synthesis procedure, namely, with the sodium-form of the resin (R-Na) and the resin after the adsorption of trivalent iron (R-Fe). It is noted that the resins, R-Fe and $\mathrm{R}-\mathrm{Na}$, cannot adsorb or reduce $\mathrm{Cr}^{+6}$. The only possible removal mechanism is via simple diffusion of the chromate anion inside the pores of the resin. When the $\mathrm{Cr}^{+6}$ solution is in contact with the R-nFe resin (after treatment with GT), the amount of removed $\mathrm{Cr}^{+6}$ is equal to 0.43 mmole per gram of $\mathrm{R}-\mathrm{nFe}$. The most probable removal mechanism with $\mathrm{R}-\mathrm{nFe}$ is the reduction of $\mathrm{Cr}^{+6}$ into $\mathrm{Cr}^{+3}$ by the encapsulated iron. Taking into consideration 
the electron donor capacity of Fe species, it is evident that zerovalent iron, $\mathrm{Fe}^{0}$, is able to reduce one mole of $\mathrm{Cr}^{+6}$ per mole of $\mathrm{Fe}^{0}$, divalent iron is able to reduce $1 / 3 \mathrm{of}^{+6}$ per mole of $\mathrm{Fe}^{+2}$, while $\mathrm{Fe}^{+3}$ is not able to affect the valence state of $\mathrm{Cr}^{+6}$. On the other hand, if the embedded $\mathrm{Fe}$ occurs in the form of $\mathrm{Fe}^{+3}$-oxides, the adsorption of $\mathrm{Cr}^{+6}$ per mole of $\mathrm{Fe}$ is significantly lower (in the order of $0.01 \mathrm{~mole} / \mathrm{mole}$ ) [70]. As seen in Figure 2, the amount of removed $\mathrm{Cr}^{+6}$ in contact with $\mathrm{R}-\mathrm{nFe}$ was almost equimolar to the amount of the total $\mathrm{Fe}$ inside the resin. It was thus deduced that during the 3rd step of the synthesis procedure, the green tea polyphenols were able to reduce the adsorbed Fe to the elemental state at a percentage of at least $73 \%$.

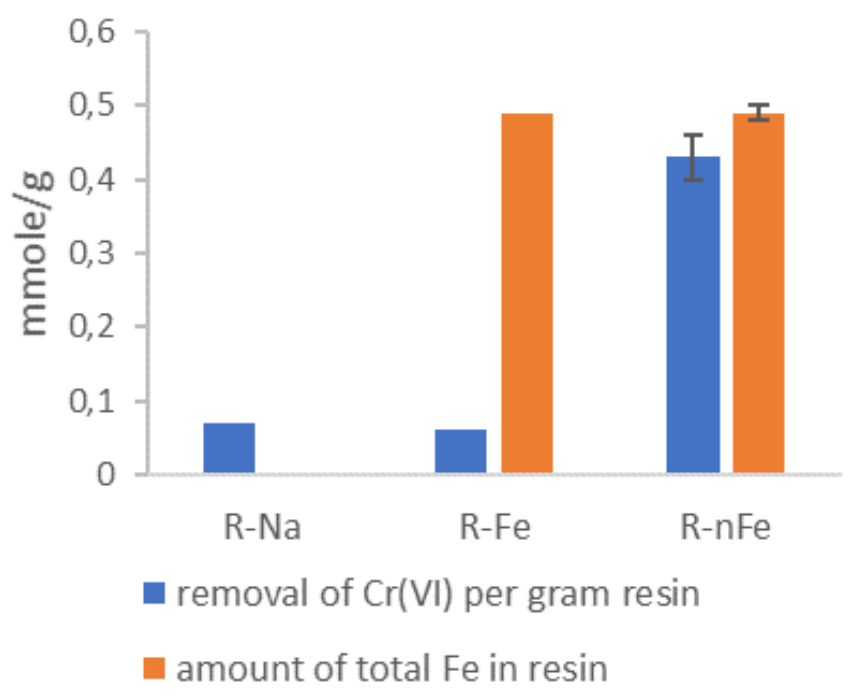

Figure 2. Evaluation of the Fe valence state inside the R-nFe beads, based on the reductive potential regarding $\mathrm{Cr}^{+6}$. The bar chart shows the removal of $\mathrm{Cr}^{+6}$ when mixed with representative samples of the resin, corresponding to the 3 steps of the synthesis procedure, i.e., R-Na, R-Fe and R-nFe.

A cut section of an R-nFe bead, as observed under the SEM, is shown in Figure 3a. Iron content was uniformly distributed in the whole section, which is an indication that nano iron remains dispersed in the interior of the resin beads after the step concerning reduction with the GT extract. The EDS analyses along the diameter are given in Figure $3 \mathrm{~b}$. A TEM microphotograph of a micro-sectioned R-nFe bead is shown in Figure 3c. The iron nanoparticles can be observed in the dark regions, while the white and gray regions represent the support resin. Iron nanoparticles have a spherical shape and size in the order of $20-40 \mathrm{~nm}$. 


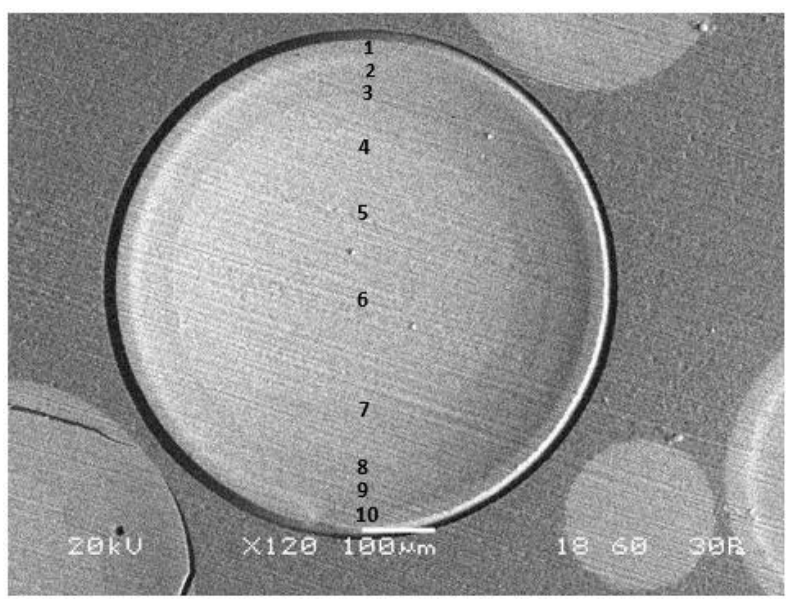

(a)

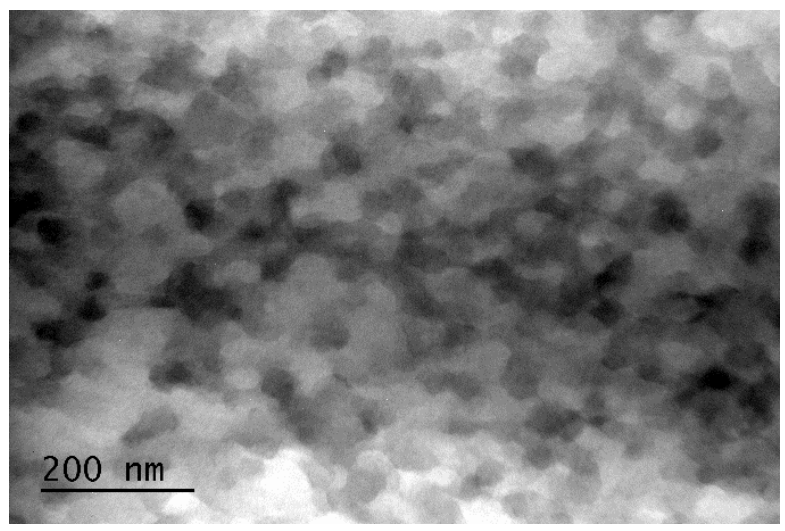

(c)

\begin{tabular}{|c|c|c|c|c|c|c|c|c|c|c|c|}
\hline \multirow[b]{2}{*}{ Element } & \multicolumn{10}{|c|}{ Atomic percentage $(\%)$} & \multirow[t]{2}{*}{ Average Value } \\
\hline & 1 & 2 & 3 & 4 & 5 & 6 & 7 & 8 & 9 & 10 & \\
\hline $\mathrm{NaK}$ & & & 0.5 & 0.4 & 0.5 & 0.6 & 0.9 & 0.3 & 0.1 & 0.4 & 0.5 \\
\hline SK & 23.4 & 23.1 & 22.7 & 23.0 & 22.8 & 23.1 & 23.0 & 22.9 & 22.8 & 22.8 & 22.9 \\
\hline Fe K & 3.3 & 3.9 & 4.2 & 3.7 & 4.0 & 3.4 & 3.3 & 4.1 & 4.3 & 4.1 & 3.9 \\
\hline 0 & 73.4 & 73.0 & 72.6 & 72.9 & 72.7 & 72.9 & 72.8 & 72.8 & 72.8 & 72.7 & 72.8 \\
\hline
\end{tabular}

(b)

Figure 3. (a) SEM microphotograph of a cut section of an R-nFe bead; (b) EDS analyses along the diameter of the cut section in (a); (c) TEM microphotograph of a microsectioned R-nFe bead.

\subsection{Effect of Contact Time}

To investigate the effect of contact time, batch experiments were performed up to $180 \mathrm{~min}$, spiking the targeted NSAIDs at an initial concentration of $1 \mu \mathrm{g} \mathrm{L}^{-1}$ and utilizing an R-nFe dose of $15 \mathrm{~g} \mathrm{~L}^{-1}$. Similar to other studies [71-75] investigating the removal of these compounds from water, a contact time of $180 \mathrm{~min}$ was initially selected as maximum. The results are presented in Figure 4. The error bars represent the standard error, which is equal to the standard deviation, divided by the square root of the number of samples. Generally, low removal efficiencies were obtained for the R-nFe dose of $15 \mathrm{~g} \mathrm{~L}^{-1}$ at a contact time of $180 \mathrm{~min}$ for all targeted compounds. More specifically, the ratios of the residual concentration at a given contact time $(\mathrm{C})$ to the initial concentration of the pollutant $\left(\mathrm{C}_{0}\right)$, denoted hereafter as $C / C_{0}$ ratios, were equal to $70 \%, 87 \%$, and $91 \%$ for NPX, DCF and IBU, respectively, whereas practically no removal was achieved for KTP. This low removal level of KTP could partially be explained by its low affinity to adsorption compared to the other target compounds, as reported in other studies [75]. However, the concentration of most targeted compounds continued to decrease in the solution after $180 \mathrm{~min}$, indicating that equilibrium was not reached. Therefore, the experiments were conducted again and continued for 2 days. The results for the larger contact time are illustrated in Figure 5a-d, noted as non-pre-treated R-nFe. The maximum removal efficiencies for all compounds were observed at the contact time of 2 days, and were equal to $75 \%$ for NPX, $71 \%$ for DCF, 
$32 \%$ for IBU and $5 \%$ for KTP. In both short and long contact times, the removal efficiencies of targeted compounds were in a decreasing order of NPX $>$ DCF $>$ IBU $>$ KTP.

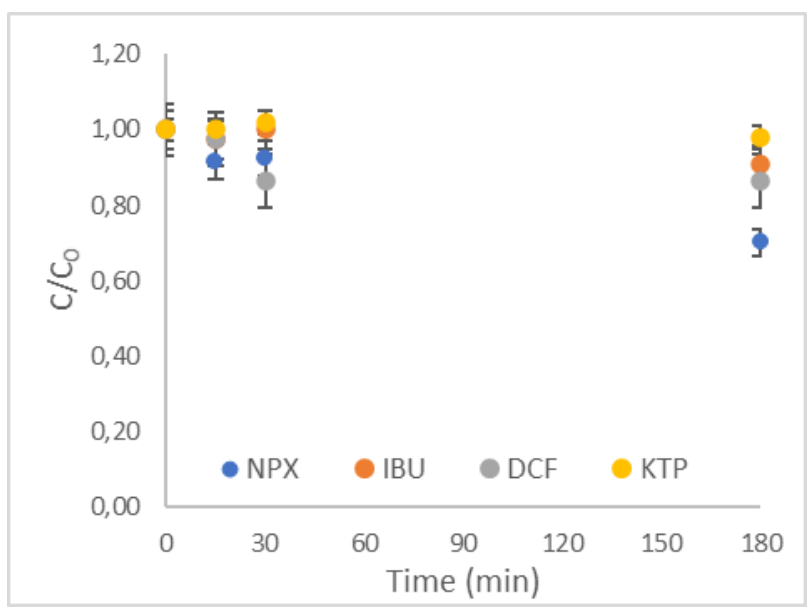

Figure 4. Effect of contact time for all selected NSAIDs (R-nFe $\left.15 \mathrm{~g} \mathrm{~L}^{-1}, \mathrm{DO} 8 \mathrm{mg} \mathrm{L}^{-1}, \mathrm{pH}=4\right)$.

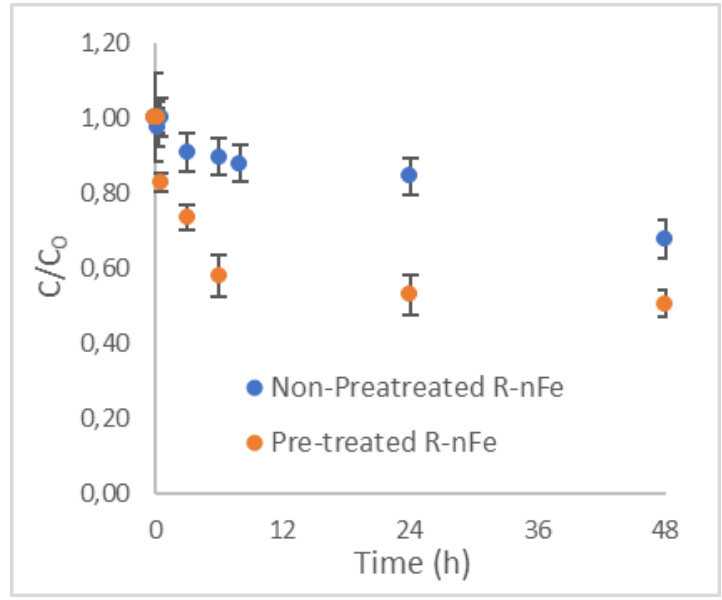

(a)

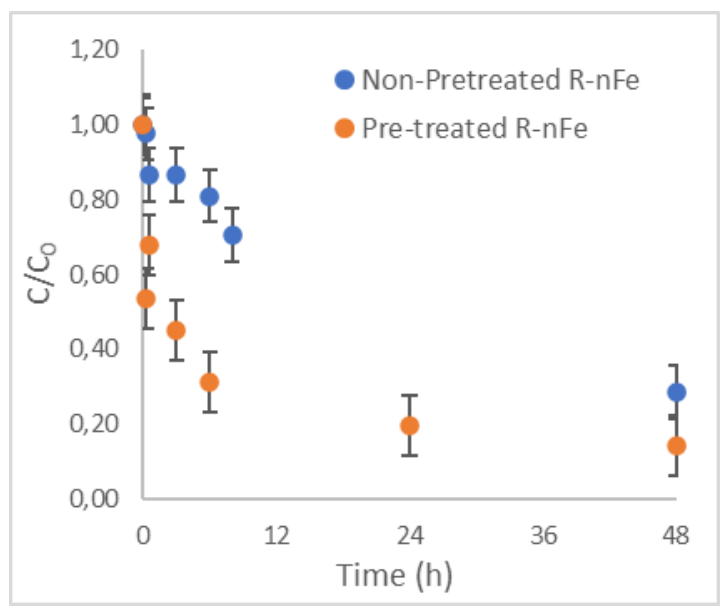

(c)

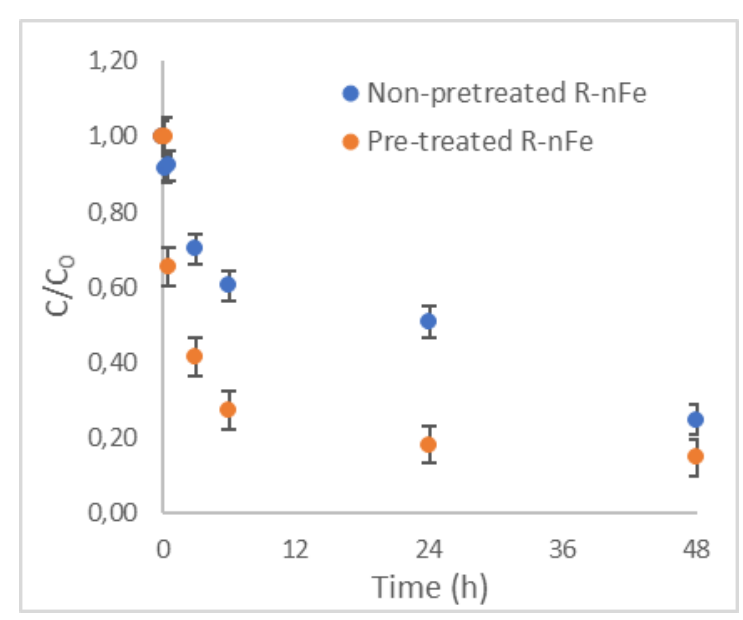

(b)

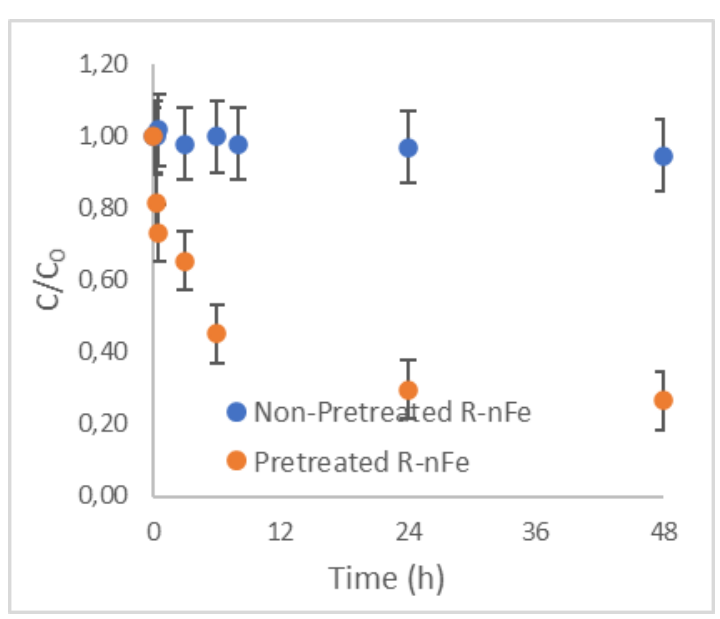

(d)

Figure 5. Effect of R-nFe pre-treatment with $\mathrm{NaCl}$ solution $1 \mathrm{M}$ for (a) IBU; (b) NPX; (c) DCF, (d) KTP. R-nFe $15 \mathrm{~g} \mathrm{~L}{ }^{-1}$, $\mathrm{pH}=4$, DO $8 \mathrm{mg} \mathrm{L}^{-1}, \mathrm{C}_{0}=1 \mu \mathrm{g} \mathrm{L}^{-1}$. 


\subsection{Effect of $\mathrm{NaCl}$ Pretreatment}

The effect of $\mathrm{NaCl}$ addition on the removal of the selected NSAIDs was evaluated as a pre-treatment step of R-nFe production. As illustrated in Figure 5, pretreatment with $\mathrm{NaCl}$ is beneficial for obtaining higher removal efficiencies for all selected NSAIDs at a given contact time. More specifically, higher removal efficiencies were observed for the longest contact time of $48 \mathrm{~h}$ in all cases; these were equal to $50 \%, 85 \%, 86 \%$ and $73 \%$ for IBU, NPX, $\mathrm{DCF}$ and $\mathrm{KTP}$, respectively.

It seems that the removal rate of all selected NSAIDs during the first $15 \mathrm{~min}$ of the experiments was limited. Between $15 \mathrm{~min}$ and $6 \mathrm{~h}$ of contact time, a significant removal rate increase occurred; thereafter, between 6 and $48 \mathrm{~h}$, only a marginal improvement is obtained. The results indicate that equilibrium can almost be reached at $24 \mathrm{~h}$ of contact time for most compounds, while this is not the case for the non-pre-treated R-nFe. While the target compounds' removal during the first 15 min could be primarily attributed to adsorption mechanisms, it is anticipated that, beyond this time, other mechanisms might be important as well (e.g., oxidation). At a contact time of $6 \mathrm{~h}$, the samples pretreated with $\mathrm{NaCl} \mathrm{R}$ nFe exhibited moderate removal efficiency for IBU and KTP ( $42 \%$ and $55 \%$, respectively) but high removal efficiency for NPX and DCF (73\% and 69\%, respectively). Therefore, it appears that a contact time of $6 \mathrm{~h}$ would be optimal with respect to the removal of target compounds in the case of adopting $\mathrm{NaCl}$ pretreatment. However, from the engineering point of view, this contact time is quite high and is practically unattainable; hence, the effect of other parameters (3.4-3.8 paragraphs) was evaluated, conducting experiments with shorter contact time (30-60 $\mathrm{min}$ ) and employing pretreatment with $\mathrm{NaCl}$.

\subsection{Effect of $p H$}

The effect of $\mathrm{pH}$ was investigated regarding the $\mathrm{R}-\mathrm{nFe}$ dose of $15 \mathrm{~g} \mathrm{~L}^{-1}$ for the selected NSAIDs, for a contact time of $30 \mathrm{~min}$. Figure 6a presents the effect of $\mathrm{pH}$ on NPX removal, whereas Figure $6 \mathrm{~b}$ illustrates the ratio of $\mathrm{C} / \mathrm{C}_{0}$ after $30 \mathrm{~min}$ of contact time for all targeted compounds. As illustrated in Figure 6a, the removal efficiency for NPX was maximized for the lower $\mathrm{pH}$ value $(\mathrm{pH}=3)$, achieving a high value $(70 \%)$ after $30 \mathrm{~min}$, whereas in neutral conditions $(\mathrm{pH}=7)$, practically no removal was observed. At the intermediate level ( $\mathrm{pH}=4)$, NPX was moderately efficiently removed from the liquid solution (35\%). Similar results were obtained for all targeted NSAIDs (Figure $6 \mathrm{~b}$ ). The highest removal efficiencies were observed for IBU and NPX, while the removal of DCF and KTP was lower, with remaining concentrations of $42 \%$ and $50 \%$, respectively. In neutral conditions $(\mathrm{pH}=7)$, all targeted compounds were poorly removed by R-nFe.

\subsection{Effect of the R-nFe Dose}

The effect of R-nFe dose was evaluated for three alternative values $\left(5,10\right.$ and $\left.15 \mathrm{~g} \mathrm{~L}^{-1}\right)$ with a $\mathrm{pH}=3$. In Figure 7a, the effect of the R-nFe dose is presented for NPX, whereas Figure $7 \mathrm{~b}$ illustrates the ratio of $\mathrm{C} / \mathrm{C}_{0}$, with a contact time of $30 \mathrm{~min}$, for all targeted compounds at $\mathrm{pH}=3$. Based on the results, the increase in the $\mathrm{R}-\mathrm{nFe}$ dose leads to improved performance, as more active sites are available for adsorption and reaction. However, in the case of NPX, the R-nFe dosing at $10 \mathrm{~g} \mathrm{~L}^{-1}$ was comparable to $15 \mathrm{~g} \mathrm{~L}^{-1}$. Evidently, no significant difference in NPX removal was obtained within $30 \mathrm{~min}$, with values being very similar and around $70 \%$. In general, for all selected NSAIDs at an initial concentration of $1 \mu \mathrm{g} \mathrm{L}^{-1}$, the R-nFe dose of $5 \mathrm{~g} \mathrm{~L}^{-1}$, was incapable of removing the compounds efficiently ( $<30 \%$ in all cases) within $30 \mathrm{~min}$, whereas with the highest dose (R-nFe $15 \mathrm{~g} \mathrm{~L}^{-1}$ ), appreciable removal efficiencies were achieved. The intermediate dose displayed moderate results in all cases, even though, in the case of DCF, the performance was closer to the one with the lower dose, achieving a rather low removal efficiency, while in the case of NPX, the performance was similar to the one with the highest dose. 


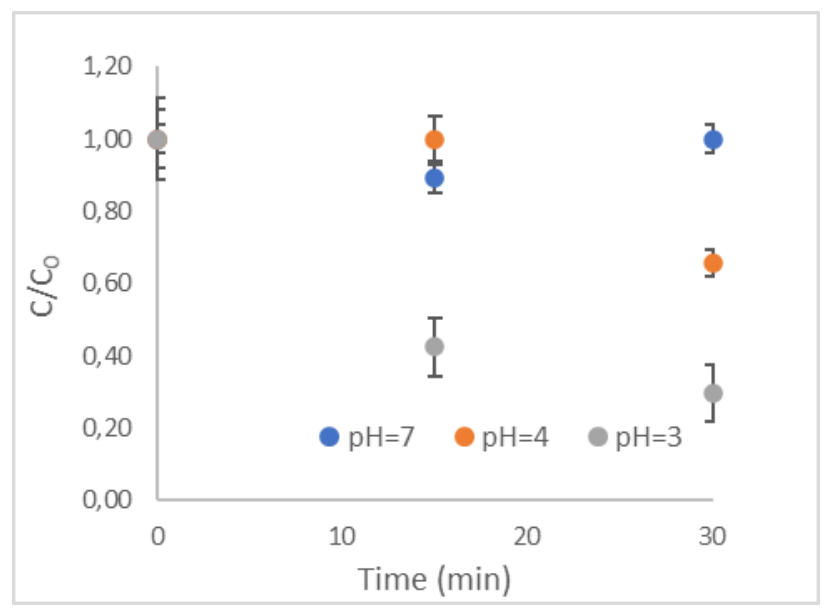

(a)

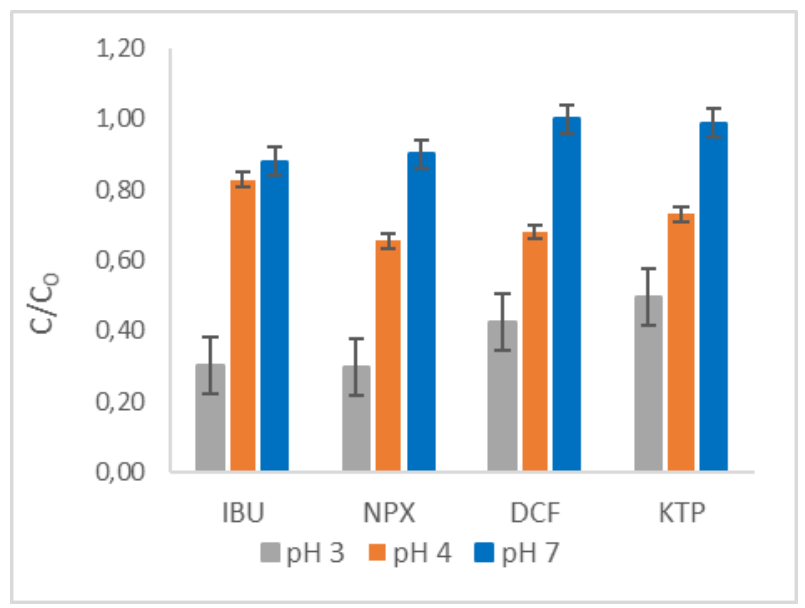

(b)

Figure 6. The effect of $\mathrm{pH}$ on (a) NPX; (b) on IBU, NPX, DCF, and KTP. R-nFe $15 \mathrm{~g} \mathrm{~L}^{-1}, \mathrm{pH}=3,4,7, \mathrm{DO} 8 \mathrm{mg} \mathrm{L}^{-1}, \mathrm{t}=30 \mathrm{~min}$, $\mathrm{C}_{0}=1 \mu \mathrm{g} \mathrm{\textrm {L } ^ { - 1 }}$.

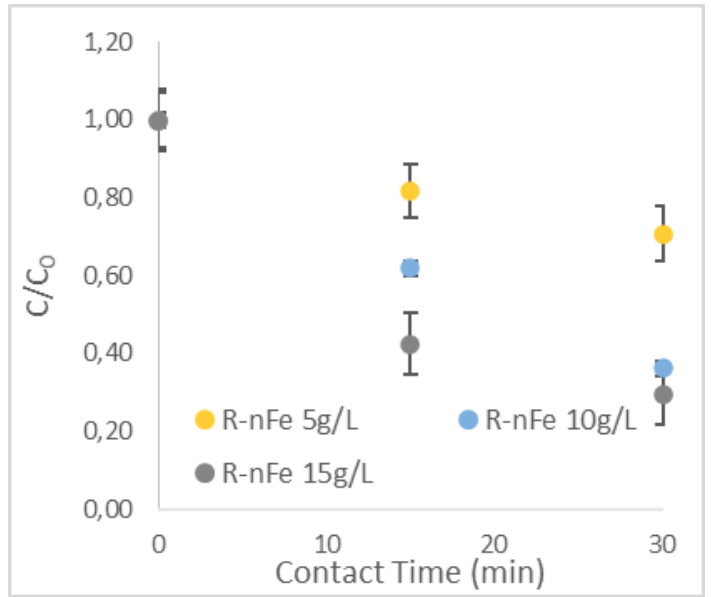

(a)

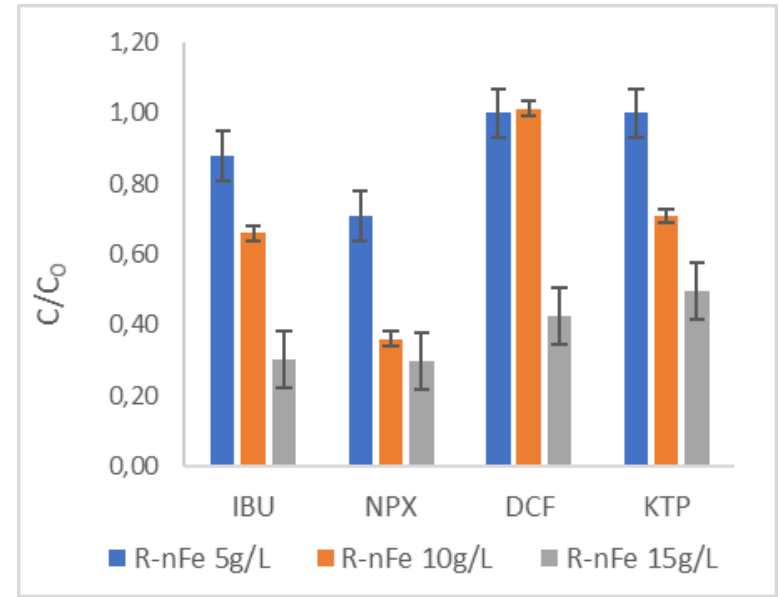

(b)

Figure 7. The effect of the R-nFe dose at a $\mathrm{pH}=3$ (a) for NPX; (b) for all selected NSAIDs at a $\mathrm{pH}=3$ and $\mathrm{t}=30 \mathrm{~min}$.

The mass of each pollutant that was removed per utilized mass of R-nFe used $\left(\mu \mathrm{g} \mathrm{g}^{-1}\right)$ varied among the selected NSAIDs. More specifically, for IBU, $0.02-0.05 \mu \mathrm{g}$ were removed per $\mathrm{g}$ of R-nFe; lesser removal occurred for the lower utilized R-nFe mass ( $5 \mathrm{~g})$, and greater removal for the higher one (R-nFe $15 \mathrm{~g}$ ). The mass of NPX that was removed per $\mathrm{g} R-\mathrm{nFe}$ was equal to $0.06 \mu \mathrm{g}$ for both experiments, with R-nFe doses of $5 \mathrm{~g}$ and $10 \mathrm{~g}$, respectively, whereas it was slightly lower $\left(0.05 \mu \mathrm{g} \mathrm{g}^{-1}\right)$ for the experiment with the R-nFe dose of $15 \mathrm{~g}$. Interestingly, the removal of DCF was practically zero when the R-nFe mass was 5-10 g, and increased to $0.04 \mu^{-1} \mathrm{~g}^{-1}$ in the case of the R-nFe dose of $15 \mathrm{~g}$. Finally, $0.03 \mu \mathrm{g}$ of KTP was removed per $\mathrm{g}$ R-nFe, for doses between 10 and $15 \mathrm{~g}$, while KTP could not be removed at an R-nFe dose of $5 \mathrm{~g}$. All in all, the total mass of all NSAIDs removed per $\mathrm{g}$ of R-nFe used was $0.08 \mu \mathrm{g} \mathrm{g}^{-1}$ for an R-nFe mass equal to $5 \mathrm{~g}$ and increased to $0.17 \mu \mathrm{g} \mathrm{g}^{-1}$ with an increase in the mass of sorbent to $15 \mathrm{~g}$. Based on these findings, the following experiments (Sections 3.6-3.8) were performed, adopting an R-nFe dose of $15 \mathrm{~g} \mathrm{~L}^{-1}$.

\subsection{The Effect of the Resin $(\mathrm{R}-\mathrm{Na})$}

The effect of the supporting material was investigated for all selected NSAIDs without the addition of nZVI. As illustrated in Figure 8 for NPX, the resin plays an important 
role in the removal of this compound, achieving approximately $50 \%$ within $30 \mathrm{~min}$ of contact time. This effect is rather significant, as the NPX removal obtained for R-nFe is only slightly higher $(70 \%)$. At the shorter contact time of $15 \mathrm{~min}$, the beneficial effect of nZVI incorporation into the resin was more profound (the difference in removal efficiency of NPX using R-nFe and R-Na was approximately $37 \%$ ). For the other target compounds (Figure 9a), the removal efficiencies achieved with R-nFe after 15 min were $47 \%$ for IBU, $37 \%$ for DCF, and $41 \%$ for KTP. At the higher contact time of $30 \mathrm{~min}$, R-nFe displayed better results for NPX and IBU, while this was not the case for DCF and KTP (Figure 9b), where practically similar results were obtained (moderate removal efficiencies for $\mathrm{R}-\mathrm{nFe}$ and $\mathrm{R}-\mathrm{Na}$, equal to $58 \%$ and $51 \%$ in the case of DCF, and $50 \%$ and $51 \%$ in the case of KTP, respectively). Furthermore, as illustrated in Figure 9a,b, the retention time exerted a significant effect on R-Na removal efficiency, as the NSAID removal obtained within 15 min ranged between 10 and $25 \%$, whereas those obtained after 30 min were almost doubled.

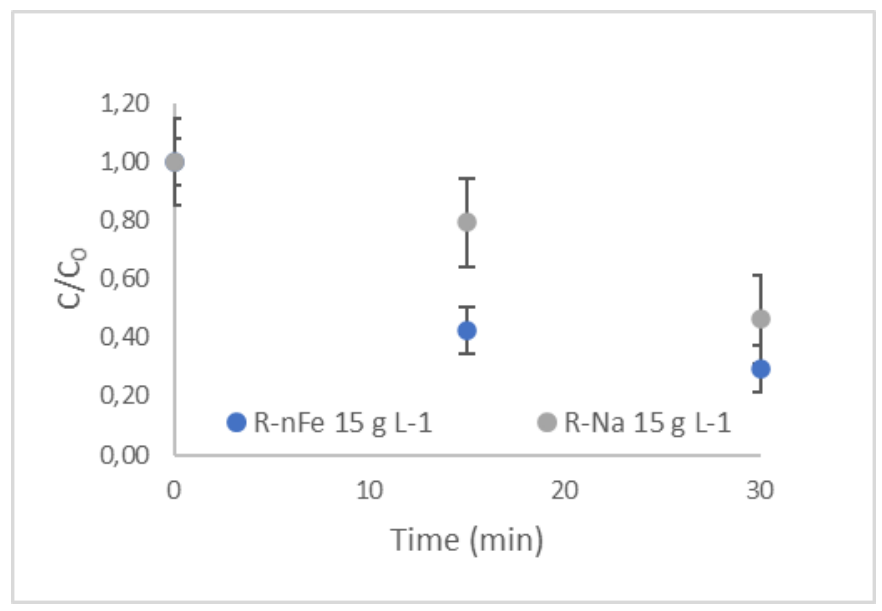

Figure 8. The role of the supporting material, R-Na, in comparison with R-nFe of the same dose in the case of NPX.



(a)

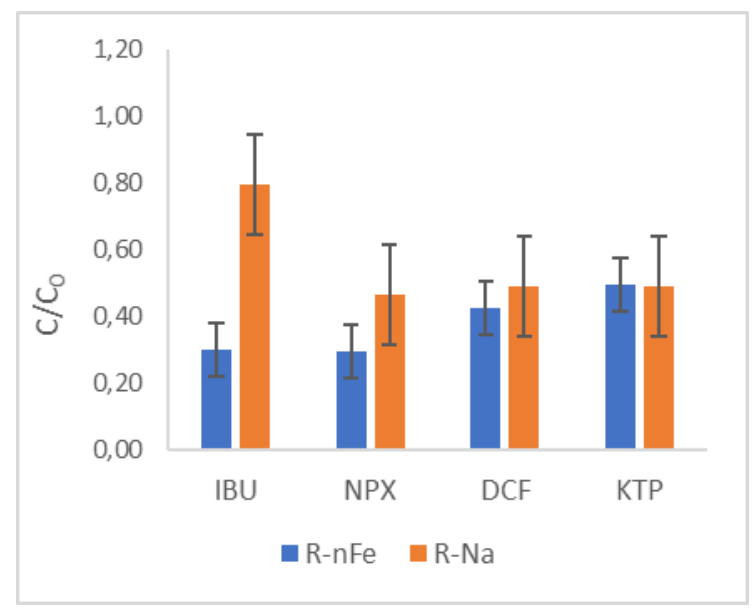

(b)

Figure 9. The role of the supporting material R-Na for all selected NSAIDs, (a) for a contact time of 15 min; (b) and for a contact time of $30 \mathrm{~min}$.

\subsection{Effect of Initial Concentration}

The effect of the initial concentration of the target compounds was evaluated using the mixture of NSAIDs at a concentration of $1 \mu \mathrm{g}$ and $10 \mu \mathrm{g} \mathrm{L}{ }^{-1}$ each. The results are presented in Figures 10 and 11. More specifically, in Figure 10, the evolution of NPX 
concentration over the 60-min experiments is illustrated, while Figure 11a,b presents the removal of the target compounds at the different initial concentrations, tested after contact times of $30 \mathrm{~min}$ and $60 \mathrm{~min}$, respectively. Under the same conditions, the increase in the initial concentration of target compounds leads to a lower removal rate and, as a result, to significantly lower removal efficiencies up to $30 \mathrm{~min}$. This was consistent for all selected NSAIDs, as depicted in Figure 11a. In addition, it seems that the R-nFe dose of $15 \mathrm{~g} \mathrm{~L}^{-1}$ does not support significant removal, obtaining low removal efficiencies $(<30 \%)$ in all experiments conducted with an initial target concentration of $10 \mu \mathrm{g} \mathrm{L}^{-1}$. On the other hand, regarding the lower initial concentration $\left(\mathrm{C}_{0} 1 \mu \mathrm{g} \mathrm{L}{ }^{-1}\right)$, high removal efficiencies were achieved (> 70\%) for IBU and NPX within the span of $30 \mathrm{~min}$, while rather moderate removal efficiencies were recorded for DCF (58\%) and KTP (50\%). However, differences in the removal efficiencies for all studied NSAIDs were not profound after $60 \mathrm{~min}$ between the two experiments. Practically similar $C / C_{0}$ ratios were observed after $30 \mathrm{~min}$ and $60 \mathrm{~min}$ for the lower initial concentration $\left(C_{0} 1 \mu \mathrm{g} \mathrm{L}^{-1}\right)$, while this was not the case for the larger initial concentration of pollutants $\left(\mathrm{C}_{0} 10 \mu \mathrm{g} \mathrm{L}^{-1}\right)$ (Figure $11 \mathrm{~b}$ ).



Figure 10. The effect of initial concentration of the pollutant $\mathrm{C}_{0} 1 \mu \mathrm{g} \mathrm{L}-1$ and $10 \mu \mathrm{g} \mathrm{L}^{-1}$ for NPX at a $\mathrm{pH}=3$.

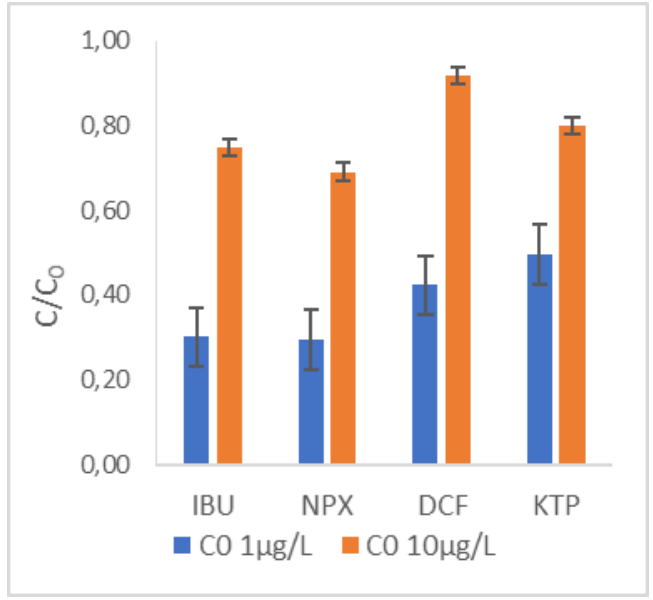

(a)

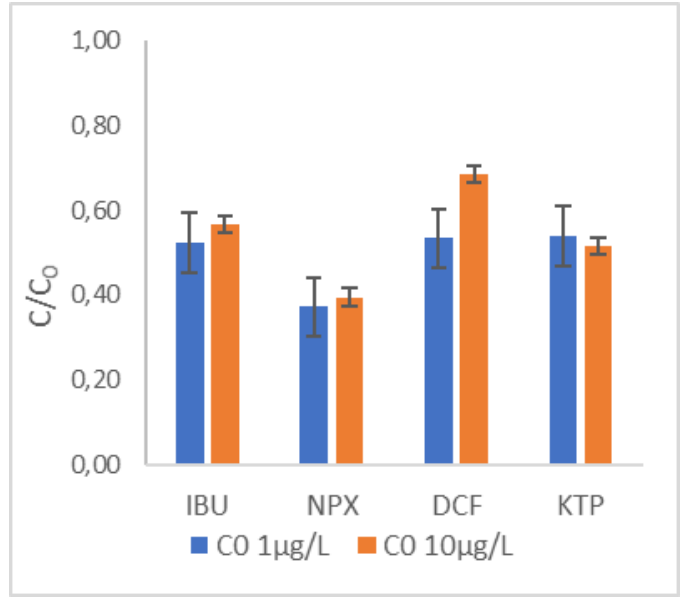

(b)

Figure 11. The effect of initial concentration of the pollutant $C_{0}$ at $1 \mu \mathrm{g} \mathrm{L}-1$ and $10 \mu \mathrm{g} \mathrm{L}-1$ for all selected NSAIDs at $\mathrm{pH}=3$, $\mathrm{R}-\mathrm{nFe} 15 \mathrm{~g} \mathrm{~L}^{-1}$, DO $8 \mathrm{mg} \mathrm{L}^{-1}$ (a) $\mathrm{t}=30 \mathrm{~min} ;(\mathbf{b}) \mathrm{t}=60 \mathrm{~min}$.

Furthermore, in the experiment using a lower initial concentration of pollutants, the specific removal capacity of R-nFe was $0.03 \mu \mathrm{g} \mathrm{g}^{-1}$ for IBU, DCF and KTP, and $0.04 \mu \mathrm{g} \mathrm{g}^{-1}$ 
for NPX, after $60 \mathrm{~min}$. The total mass removed per $\mathrm{g}$ of sorbent was $0.14 \mu \mathrm{g} \mathrm{g}-1$ after $60 \mathrm{~min}$ in the case of the lowest initial concentration of pollutants, and corresponds to a moderate overall removal of $51 \%$ of the total initial mass of the pollutants $(4 \mu \mathrm{g})$. In contrast, the specific removal capacity of R-nFe in the case of the higher initial concentration of pollutants was approximately 7-10 times higher, ranging from 0.21 to $0.40 \mu \mathrm{g} \mathrm{g}^{-1}$ for IBU, NPX, DCF and KTP after $60 \mathrm{~min}$. The total mass removed per $\mathrm{g}$ of sorbent was $1.22 \mu \mathrm{g} \mathrm{g}^{-1}$ after $60 \mathrm{~min}$ and also corresponds to a moderate overall removal of $46 \%$ of the initial mass of the pollutants $(40 \mu \mathrm{g})$.

\subsection{Effect of Oxidative Reagents Addition}

The combined utilization of nZVI with strong oxidative agents, namely, hydrogen peroxide $\left(\mathrm{H}_{2} \mathrm{O}_{2}\right)$ and sodium persulfate (PS), was investigated in order to establish the effect of the Fenton reaction on targeted compound removal. The experiments were performed at a contact time of $60 \mathrm{~min}$ and with an initial concentration of pollutants at $10 \mu \mathrm{g} \mathrm{L}^{-1}$, in order to obtain removal kinetics before the substances are completely removed. Initially, control experiments were performed with the addition of $1 \mathrm{mM} \mathrm{H}_{2} \mathrm{O}_{2}$ and PS in the absence of $\mathrm{R}-\mathrm{nFe}$ (denoted in the following figures as " $\mathrm{C}$ "). Figure 12a presents the effect of the addition of the oxidative reagents, $\mathrm{H}_{2} \mathrm{O}_{2}$ and $\mathrm{PS}$, at $1 \mathrm{mM}$ concentration with and without the addition of R-nFe $15 \mathrm{~g} \mathrm{~L}^{-1}$ for NPX. Figure $12 \mathrm{~b}$ illustrates the ratio of $\mathrm{C} / \mathrm{C}_{0}$ after $60 \mathrm{~min}$ of contact time for all targeted compounds. Data on NPX (Figure 12a) indicate that at a contact time of $60 \mathrm{~min}$, the dose of $1 \mathrm{mM} \mathrm{H}_{2} \mathrm{O}_{2}$ is practically insufficient to obtain high NPX removal efficiencies at a $\mathrm{pH}=3$, with the $\mathrm{C} / \mathrm{C}_{0}$ ratio being around $75 \%$. The addition of $1 \mathrm{mM}$ of PS resulted in moderate NPX removal, similar to that obtained with R-nFe alone without the addition of oxidative agents. However, improved removal efficiencies were obtained when R-nFe was combined with an oxidative agent. The optimum results were obtained in the case of R-nFe and PS $(1 \mathrm{mM})$, with removal efficiencies of the order of $90 \%$ for NPX. This was also the case for DCF, but the removal efficiency was lower (49\%). For IBU and KTP, the removal efficiencies achieved for both combinations were moderate but were better than those observed with $\mathrm{R}-\mathrm{nFe}, \mathrm{H}_{2} \mathrm{O}_{2}$ and $\mathrm{PS}$ alone. IBU and KTP removal efficiency in the $\mathrm{R}-\mathrm{nFe} / \mathrm{H}_{2} \mathrm{O}_{2}$ systems was $44 \%$, and IBU and KTP removals in R-nFe/PS systems were $41 \%$ and $37 \%$, respectively.

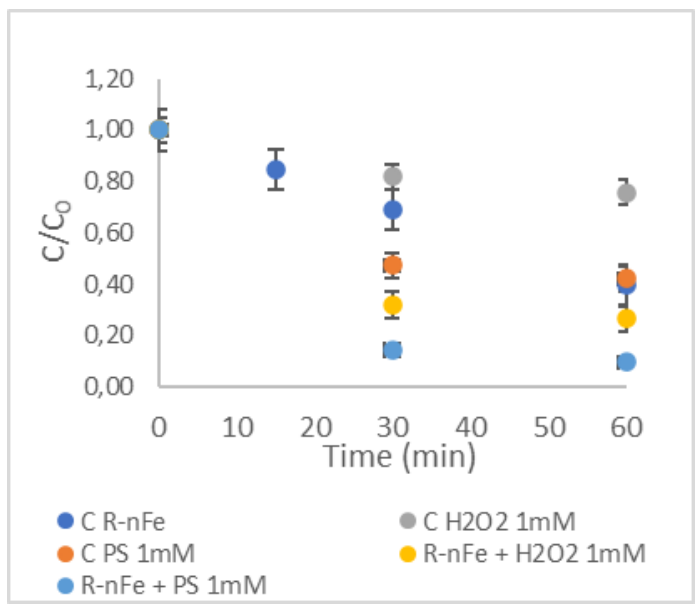

(a)

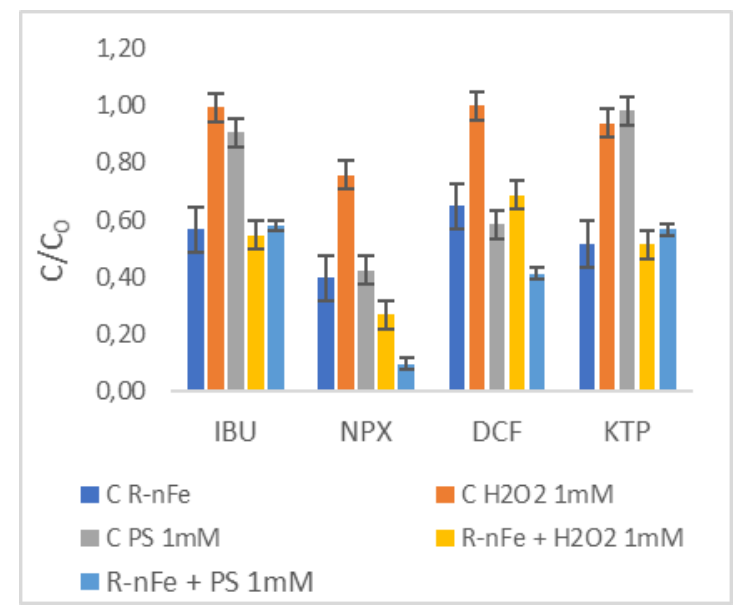

(b)

Figure 12. The effect of the oxidative reagents $\mathrm{H}_{2} \mathrm{O}_{2}$ and PS $1 \mathrm{mM}$ with and without the addition of R-nFe $15 \mathrm{~g} \mathrm{~L}^{-1}$ (a) for $\mathrm{NPX}$, (b) for all targeted compounds, at $\mathrm{pH}=3, \mathrm{DO}=8 \mathrm{mg} \mathrm{L}^{-1}$ and after $60 \mathrm{~min}$ of contact time. 


\section{Discussion}

In this study, the performance of nZVI produced via an environmentally friendly method and incorporated into a cationic resin was assessed for removing selected NSAIDs by conducting batch experiments.

More specifically, the present work was carried out using GT extract as a source of polyphenols for the reduction of iron. GT is a commercial product with well-known antioxidant properties, related to its high polyphenol content. Machado et al. [47] have demonstrated that several other plant extracts originating from agricultural or garden wastes, e.g., tree leaves, vine leaves, grape marc, etc., can also be valorized and used as polyphenol sources for the synthesis of nZVI particles. The recycling and transformation of agricultural waste to produce high added-value materials can significantly reduce the carbon footprint and increase the environmental and economic sustainability of the processes involved [48].

Regarding the effect of contact duration, the contact time of 180 min was not sufficient for obtaining significant removal efficiencies for all targeted compounds (Figure 4) when utilizing R-nFe without pretreatment. Similar findings have been reported by other studies as well. Evidently, Dong et al. [76] found that ZVI without the addition of oxidative reagent achieved negligible NPX removal after a contact time of $30 \mathrm{~min}$. Zhou et al. [77] tested commercial mZVI and lab-synthesized ZVI-graphite and found the IBU removal to be negligible after $20 \mathrm{~h}$. However, higher removal efficiencies were recorded with the increase in contact time to $2 \mathrm{~d}$ (Figure 5). As the experiments were conducted under aerobic conditions, and it is likely that nZVI in the presence of oxygen may initiate Fenton reactions $[46,78]$ even without the addition of oxidative reagents, the observed removal efficiencies could be attributed to both adsorption and oxidation mechanisms.

Based on the results, $\mathrm{NaCl}$ pre-treatment of $\mathrm{R}-\mathrm{nFe}$ appears to significantly improve the removal of targeted compounds (Figure 5). $\mathrm{NaCl}$ is considered to enhance nZVI corrosion, thus increasing its reactivity with the target pollutants. This result is in accordance with the findings of Ghauch et al. [36], who studied the performance of nZVI material for the removal of two common antibiotics and reported that low concentrations of $\mathrm{NaCl}$ led to high removal efficiencies. On the other hand, Mo et al. [79] found that increasing $\mathrm{Cl}^{-}$anion concentrations from 0 to $1 \mathrm{M}$ decreased the removal of DCF and KTP through adsorption in metal-organic frameworks, because the dissociation of $\mathrm{Cl}^{-}$from $\mathrm{NaCl}$ addition inhibits the reactions between DCF and KTP with the adsorbents. Zhang et al. [80], who studied anionic resins, found that an increase in $\mathrm{NaCl}$ concentration leads to a decrease in IBU adsorption into the active sites of the resin, due to competition for ion chlorides with the anions of IBU; Van Tran et al. [72], who studied IBU adsorption in hollow mesoporous carbon, found that $\mathrm{NaCl}$ has a negative effect because IBU is in a cationic state in $\mathrm{pH}<\mathrm{pKa}$ and an increase in $\mathrm{Na}^{+}$leads to an antagonistic environment. However, in the experiments performed in this work, the $\mathrm{pH}$ was close to the $\mathrm{pKa}$ values of the NSAIDs, showing that the compounds were in neutral form, and thus $\mathrm{NaCl}$ could not have affected adsorption. Therefore, $\mathrm{NaCl}$ pre-treatment may have balanced the external and internal pressures, enhancing the diffusion of the polluting compounds from the medium into the pores of the resin.

Regarding the effect of $\mathrm{pH}$, acidic conditions favor the removal of targeted NSAIDs with R-nFe (Figure 6). The dominant role of $\mathrm{pH}$ on the degradation of NSAIDs has been reported in several studies; usually, it affects NSAID removal through adsorption [80-83]. For example, Al Othman et al. [84] showed that the maximum adsorption of DCF was achieved at a $\mathrm{pH}=5(85 \%)$ due to the carboxylic group in its molecule, resulting in the anionic form of the compound. Furthermore, they reported that even if the surface charge of the adsorbent becomes neutral, $\pi-\pi$ interactions retained the adsorbed DCF in the adsorbent, as DCF can act as a $\pi$-electron acceptor and $\pi-\pi$ interactions can be created with the benzene structure of the adsorbent. However, when utilizing nZVI in the presence of oxygen, other mechanisms apart from adsorption may be activated for degrading the pollutants. Zhou et al. [77] utilized nZVI for DCF removal and found that acidic conditions 
favor NSAID removal under aerobic conditions; they proposed that the oxidation of DCF takes place through radicals generated from Fenton-like reactions at $\mathrm{pH}$ values $<4$, whereas at a $\mathrm{pH}$ range of between 4 and 7 , oxidation and adsorption are the main mechanisms. $\mathrm{pH}$ values $>7$ enable the physical adsorption of DCF, which takes place in the $\mathrm{FeOOH}^{-}$ shell of the nZVI. Another study performed by Zhang et al. [80] reports maximum IBU adsorption into the adsorbent at $\mathrm{pH}$ values close to its $\mathrm{pKa}$ value (4.17), whereas in the case of $\mathrm{pH}$ values < $\mathrm{pKa}$, IBU removal decreased because the molecular form of IBU did not support electrostatic mechanism reactions taking place. All in all, the removal of all targeted compounds in our study was maximized at the lower $\mathrm{pH}$ value investigated $(\mathrm{pH}=3)$, which may be attributed to adsorption via electrostatic interactions. The reason is that the $\mathrm{pKa}$ of all targeted NSAIDs ranges between 4.14 and 4.59; thus, at lower $\mathrm{pH}$ values, those compounds that are characterized as weak acids are neutrally charged and, at higher $\mathrm{pH}$ values, they exist in the anionic form [82], whereas resin and nZVI has a positive surface charge at $\mathrm{pH}$ values $<7[85,86]$. Other mechanisms of adsorption, such as hydrophobic interactions, $\pi$-cation interaction, and hydrogen bonding in combination with Fenton reactions in the presence of oxygen and nZVI may be also responsible for the removal rates obtained. For DCF in particular, which has a chlorinated ring, reductive dichlorination can take place via the transfer of electrons from the nZVI surface [87].

Moreover, adopting a higher R-nFe dose resulted in higher removal capacity for all targeted NSAIDs (Figure 7). The increase in the R-nFe dose increases the availability of active sites where adsorption and interaction can take place between nZVI and NSAIDs. Ali et al. [88] reported increased removal efficiencies of IBU with an increase in the adsorbent's dose but this was only up to a maximum point, after which additional material could not lead to higher removal efficiencies. The same conclusion was reached by Soares et al. [82] regarding DCF, KTP and NPX, using a chitosan-based magnetic nano adsorbent. In this study, the use of R-nFe at $15 \mathrm{~g} \mathrm{~L}^{-1}$ was the maximum dose investigated and the effect was positive, meaning that the full extent of the material's capacity regarding these compounds was not reached. In parallel, it should also be noted that in many studies, experiments are performed to obtain the removal efficiency of a single NSAID and do not refer to multiple-NSAID matrixes, as presented in this study. Accordingly, the removal efficiency obtained in the literature for a specific NSAID may vary, depending on the concentrations of other pollutants, even if the same experimental conditions are applied; this should be considered when comparing the results of different treatment methods with nZVI. For example, Liu et al. [89] observed that when multiple NSAIDs exist in a solution, the removal efficiencies are decreased compared to single-NSAID systems by approximately $10 \%$. The same study reports that the existence of hydrophobic substances and oils decreases the removal efficiency of NSAIDs with electrocoagulation-flotation. As these drugs are quite similar regarding their physicochemical characteristics, they may compete for vacant sites in the active porous areas of the resin.

The maximum specific removal capacity of R-nFe achieved in our work was $0.17 \mu \mathrm{g} \mathrm{g}^{-1}$ for the total mass of the pollutants. In comparison with the aforementioned studies [82,88], which utilized other types of iron nano adsorbents, this capacity does not seem to be substantial, suggesting that larger doses of R-nFe should be investigated and that the employment of R-nFe in Fenton processes could be more cost-effective than utilizing R-nFe as a stand-alone process.

Furthermore, the increase in initial pollutants concentration leads to a decrease in the removal efficiencies of the targeted compounds under the same experimental conditions (Figures 10 and 11). The active sites in the pores of the resin, and the reactivity of nZVI are diminishing, as the initial concentration of pollutants increases and the rate of removal decreases. Dong et al. [76] also observed that when increasing the initial concentration of NPX from 5-25 $\mu \mathrm{M}$, the rate of removal decreases in the ZVI/PS system. This was attributed to the increased ratio of NPX to oxidative radicals. On the other hand, Ali et al. [88], who studied the removal of IBU from water using an iron nano adsorbent, found that the removal efficiency of DCF increased with the increase in the initial concentration 
until a maximum concentration point, where adsorption could not be further enhanced. $\mathrm{Al}$ Othman et al. [84] also reached the same conclusion. The maximum removal capacity of R-nFe achieved in this study was $1.22 \mu \mathrm{g} \mathrm{g}^{-1}$ for the total mass of the pollutants in the experiment at a higher initial concentration $\left(\mathrm{C}_{0} 10 \mu \mathrm{g} \mathrm{L}{ }^{-1}\right)$. Al-Rimawi et al. [90], who investigated the removal of NSAIDs, among other pharmaceuticals, using zeolite, reached the same conclusion and attributed this trend to the increased driving force helping to overcome mass transfer limitations and enhance adsorption onto the sorbent's surface.

The effect of the supporting material seems to be important for NSAID removal (Figures 8 and 9). Although the resin used was capable of exchanging cations, it could also abet the adsorption of the targeted compounds, promoting other interactions and bonding mechanisms, along with nZVI. Having an anionic resin may promote targeted compound removal because it further enhances the occurrence of electrostatic interactions as well. For example, Mo et al. [79] attributed DCF and KTP adsorption to electrostatic forces between the highly positive charge of the ionic covalent organic frameworks (iCOFs) that led to the attraction of anions to its surface; however, the feasibility of incorporating nZVI in anionic resin should be investigated. It should be noted that only a relatively small number of studies consider the effect of nZVI's supporting material or its modification-especially when nZVI is used as a nanocomposite-on the removal of pollutants, even though this effect can be significant.

Finally, the combination of nZVI with advanced oxidation methods seems optimal for the removal of NSAIDs (Figure 12). R-nFe exhibited better performance when utilized in $\mathrm{nZVI} / \mathrm{H}_{2} \mathrm{O}_{2}$ and nZVI/PS systems. This was in agreement with other studies [76,91]. For example, Wu et al. [44], who investigated the performance of both $\mathrm{H}_{2} \mathrm{O}_{2}$ and PS combined with nZVI, suggested this as a more economically sustainable method to remove pharmaceuticals from water. Furthermore, Liang et al. [87] demonstrated the improved removal efficiency of DCF when nZVI was combined with $\mathrm{H}_{2} \mathrm{O}_{2}$. Therefore, this practice may offer a promising method for treating recalcitrant pharmaceutical compounds at trace-level concentrations.

In view of all the aforementioned studies, and to the best of our knowledge, this is the first time that nZVI, produced with the utilization of leaf extracts and incorporated into a cationic resin, has been used to remove pharmaceuticals from water. The cationic resin serving as the supporting material is capable of adsorbing iron cations $\left(\mathrm{Fe}^{+2} / \mathrm{Fe}^{+3}\right)$, recirculating iron into the treatment system and promoting further reactions with the target pollutants. Thus, the proposed method is not expected to release nanoparticles that may affect living microorganisms in soil and water. Another advantage of the method is that nZVI is produced utilizing herbal extracts, instead of the common synthesis method with $\mathrm{NaBH}_{4}$, offering a more sustainable method for removing micropollutants.

However, it should be mentioned that possible limitations of the method should be further investigated to explore its overall sustainability. A matter of concern refers to the possible limitations presented by the complex wastewater matrix, which might possibly result in a higher contact time and/or nZVI dose.

Furthermore, the possibility of regenerating and reusing R-nFe, after the exhaustion of its remedial capacity, is a crucial aspect of the final evaluation of the sustainability of this technology. The exhaustion of nZVI particles is characterized by the gradual oxidation of elemental iron, $\mathrm{Fe}^{0}$, into $\mathrm{Fe}^{+3}$ species. Depending on the operating $\mathrm{pH}$, the oxidized iron remains inside the pores of the resin beads, as soluble cations are retained by electrostatic forces via the sulfonate functional groups of the resin, or as solid iron oxyhydroxide precipitates. Regeneration of the R-nFe composite material can be carried out by applying a four- or a two-step treatment. The four-step regeneration treatment was tested in a similar R-nFe product that was used for $\mathrm{Cr}^{+6}$ removal from contaminated water [67]. It involved an initial treatment of the exhausted resin beads with a strongly acidic solution, $2 \mathrm{~N} \mathrm{HCl}$, to wash out all $\mathrm{Fe}^{+3}$ species, including the reduced $\mathrm{Cr}^{+3}$ species. The bare resin beads were then treated with all the steps of the synthesis procedure, as described in Figure 1. In that study, regeneration was conducted 3 times, and $\mathrm{Cr}^{+6}$ removal remained 
very high, with a slight decrease of effectiveness from $96 \%$ in the fresh R-nFe to $87 \%$ after the third regeneration cycle. When R-nFe is used for the removal of organic contaminants, regeneration can be carried out by applying only a two-step treatment. The exhausted $\mathrm{R}-\mathrm{nFe}$ can be treated with a less acidic solution, e.g., $0.1 \mathrm{M} \mathrm{HCl}$, in order to dissolve the $\mathrm{Fe}^{+3}$ precipitates and remove the adsorbed species. It is anticipated that the main part of the $\mathrm{Fe}^{+3}$ cations will remain inside the resin beads, electrostatically attracted by the sulfonate functional groups. The second step will be the treatment of R-Fe with plant polyphenols in order to reduce the trivalent cation $\mathrm{Fe}^{+3}$ into its elemental state, $\mathrm{Fe}^{0}$.

\section{Conclusions}

To summarize, the proposed method, employing nZVI made of green tea extracts and incorporated in a cationic resin, seems to be a promising method for removing NSAIDs from water. An increase in contact time, $\mathrm{NaCl}$ pretreatment and $\mathrm{R}-\mathrm{nFe}$ dose were beneficial for process performance, whereas the increase of $\mathrm{pH}$ from acidic to neutral values and the increase of the initial concentration of the pollutants had negative effects on removal efficiency. In addition, the supporting material played a significant role in the removal of almost all targeted NSAIDs.

The best removal efficiencies obtained for DCF and KTP were $86 \%$ and $73 \%$, respectively, after $48 \mathrm{~h}$ of contact time, with NaCl-pretreated R-nFe at a dose of $15 \mathrm{~g} \mathrm{~L}^{-1}$ and $\mathrm{pH}=4$. The removal efficiency for NPX was $86 \%$ under the same conditions, quite similar to that obtained for the experiment with the PS addition. The maximum IBU removal value was $70 \%$ and was reached at $\mathrm{pH} 3$, with a contact time of 30 min and $\mathrm{R}-\mathrm{nFe} 15 \mathrm{~g} \mathrm{~L}^{-1}$. However, the process performance of R-nFe was enhanced with the addition of oxidative reagent; in particular, PS addition resulted in a significantly shorter contact time for an increased initial concentration of pollutants. The maximum removal efficiencies recorded in combined systems were $44 \%$ for IBU and KTP in the nZVI $/ \mathrm{H}_{2} \mathrm{O}_{2}$ system, and $90 \%$ and $49 \%$ for NPX and DCF, respectively, in the nZVI/PS system with a contact time of $60 \mathrm{~min}$, a pH of 3 , and $\mathrm{C}_{0}$ at $10 \mu \mathrm{g} \mathrm{\textrm {L } ^ { - 1 }}$.

Therefore, future research should focus on systems combining nZVI synthesized from herbal extracts with oxidative reagents for the removal of NSAIDs. However, potential limitations and drawbacks of the proposed method should be addressed. For example, the synthesis procedure at full scale may be challenging; in addition, the effectiveness of the $\mathrm{R}$-nFe material after multiple cycles of operation, its reusability and regeneration should be further investigated. In addition, more complex matrices should be tested to evaluate the performance of the method using real wastewater, in order that this treatment method may be implemented on a larger scale.

Author Contributions: Conceptualization, C.N., S.M., I.P. and D.M.; methodology, C.M., N.P. and I.P.; investigation, M.K., E.B., I.P. and E.K.; writing — original draft preparation, I.P.; writing—review and editing, C.N., S.M., D.M., C.M., N.P., E.B. and E.K.; supervision, C.N. All authors have read and agreed to the published version of the manuscript.

Funding: This research was funded by the Partnership on Research and Innovation in the Mediterranean Area (PRIMA), as part of the project "Safe and Sustainable Solutions for the Integrated Use of Non-Conventional Water Resources in the Mediterranean Agricultural Sector (FIT4REUSE)", grant number [1823][FIT4REUSE][Call 2018 Section 1 Water]. The PRIMA Program is supported under the Horizon 2020, the European Union's Framework Program for Research and Innovation.

Data Availability Statement: This statement is excluded as no data are reported.

Acknowledgments: This study was carried out as part of the project "Safe and Sustainable Solutions for the Integrated Use of Non-Conventional Water Resources in the Mediterranean Agricultural Sector (FIT4REUSE)" which has received funding from the Partnership on Research and Innovation in the Mediterranean Area (PRIMA) under grant agreement No 1823. PRIMA is supported by the European Union's Horizon 2020 research and innovation program. 
Conflicts of Interest: The authors declare no conflict of interest. The funders had no role in the design of the study; in the collection, analyses, or interpretation of data; in the writing of the manuscript, or in the decision to publish the results.

\section{References}

1. Wilkinson, J.; Hooda, P.S.; Barker, J.; Barton, S.; Swinden, J. Occurrence, Fate and Transformation of Emerging Contaminants in Water: An Overarching Review of the Field. Environ. Pollut. 2017, 231, 954-970. [CrossRef]

2. Rosenfeld, P.E.; Feng, L.G.H. 16-Emerging Contaminants. In Risks of Hazardous Wastes; Rosenfeld, P.E., Feng, L.G.H., Eds.; William Andrew Publishing: Boston, FL, USA, 2011; pp. 215-222. [CrossRef]

3. Tang, Y.; Yin, M.; Yang, W.; Li, H.; Zhong, Y.; Mo, L.; Liang, Y.; Ma, X.; Sun, X. Emerging Pollutants in Water Environment: Occurrence, Monitoring, Fate, and Risk Assessment. Water Environ. Res. 2019, 91, 984-991. [CrossRef] [PubMed]

4. Wintgens, T.; Salehi, F.; Hochstrat, R.; Melin, T. Emerging Contaminants and Treatment Options in Water Recycling for Indirect Potable Use. Water Sci. Technol. J. Int. Assoc. Water Pollut. Res. 2008, 57, 99-107. [CrossRef]

5. Sauvé, S.; Desrosiers, M. A Review of What Is an Emerging Contaminant. Chem. Cent. J. 2014, 8, 15. [CrossRef]

6. Tyumina, E.A.; Bazhutin, G.A.; Cartagena Gómez, A.D.P.; Ivshina, I.B. Nonsteroidal Anti-Inflammatory Drugs as Emerging Contaminants. Microbiology 2020, 89, 148-163. [CrossRef]

7. Praveenkumarreddy, Y.; Vimalkumar, K.; Ramaswamy, B.R.; Kumar, V.; Singhal, R.K.; Basu, H.; Gopal, C.M.; Vandana, K.E.; Bhat, K.; Udayashankar, H.N.; et al. Assessment of Non-Steroidal Anti-Inflammatory Drugs from Selected Wastewater Treatment Plants of Southwestern India. Emerg. Contam. 2021, 7, 43-51. [CrossRef]

8. Bickley, L.K.; van Aerle, R.; Brown, A.R.; Hargreaves, A.; Huby, R.; Cammack, V.; Jackson, R.; Santos, E.M.; Tyler, C.R. Bioavailability and Kidney Responses to Diclofenac in the Fathead Minnow (Pimephales Promelas). Environ. Sci. Technol. 2017, 51, 1764-1774. [CrossRef]

9. Han, S.; Choi, K.; Kim, J.; Ji, K.; Kim, S.; Ahn, B.; Yun, J.; Choi, K.; Khim, J.S.; Zhang, X.; et al. Endocrine Disruption and Consequences of Chronic Exposure to Ibuprofen in Japanese Medaka (Oryzias latipes) and Freshwater Cladocerans Daphnia Magna and Moina Macrocopa. Aquat. Toxicol. Amst. Neth. 2010, 98, 256-264. [CrossRef]

10. Lei, M.; Zhang, L.; Lei, J.; Zong, L.; Li, J.; Wu, Z.; Wang, Z. Overview of Emerging Contaminants and Associated Human Health Effects. BioMed Res. Int. 2015, 2015, e404796. [CrossRef]

11. Conaghan, P.G. A Turbulent Decade for NSAIDs: Update on Current Concepts of Classification, Epidemiology, Comparative Efficacy, and Toxicity. Rheumatol. Int. 2012, 32, 1491-1502. [CrossRef] [PubMed]

12. Fokunang, C. Overview of Non-Steroidal Anti-Inflammatory Drugs (Nsaids) in Resource Limited Countries. MOJ Toxicol. 2018, 4, 81. [CrossRef]

13. Wongrakpanich, S.; Wongrakpanich, A.; Melhado, K.; Rangaswami, J. A Comprehensive Review of Non-Steroidal AntiInflammatory Drug Use in The Elderly. Aging Dis. 2018, 9, 143-150. [CrossRef] [PubMed]

14. Ahmed, M.J. Adsorption of Non-Steroidal Anti-Inflammatory Drugs from Aqueous Solution Using Activated Carbons: Review. J. Environ. Manag. 2017, 190, 274-282. [CrossRef]

15. Kim, S.; Chu, K.H.; Al-Hamadani, Y.A.J.; Park, C.M.; Jang, M.; Kim, D.-H.; Yu, M.; Heo, J.; Yoon, Y. Removal of Contaminants of Emerging Concern by Membranes in Water and Wastewater: A Review. Chem. Eng. J. 2018, 335, 896-914. [CrossRef]

16. Almeida, H.F.D.; Marrucho, I.M.; Freire, M.G. Removal of Non-Steroidal Anti-Inflammatory Drugs from Aqueous Environments with Reusable Ionic-Liquid-Based Systems. ACS Sustain. Chem. Eng. 2017, 5, 2428. [CrossRef] [PubMed]

17. Ensano, B.M.B.; Borea, L.; Naddeo, V.; Belgiorno, V.; De Luna, M.D.G.; Ballesteros, F.C. Removal of Pharmaceuticals from Wastewater by Intermittent Electrocoagulation. Water 2017, 9, 85. [CrossRef]

18. González, O.; Bayarri, B.; Aceña, J.; Pérez, S.; Barceló, D. Treatment Technologies for Wastewater Reuse: Fate of Contaminants of Emerging Concern. In Advanced Treatment Technologies for Urban Wastewater Reuse; Fatta-Kassinos, D., Dionysiou, D.D., Kümmerer, K., Eds.; The Handbook of Environmental Chemistry; Springer International Publishing: Cham, Switzerland, 2016; pp. 5-37. [CrossRef]

19. Villanueva-Rodríguez, M.; Bello-Mendoza, R.; Hernández-Ramírez, A.; Ruiz-Ruiz, E.J. Degradation of Anti-Inflammatory Drugs in Municipal Wastewater by Heterogeneous Photocatalysis and Electro-Fenton Process. Environ. Technol. 2019, 40, 2436-2445. [CrossRef]

20. Quero-Pastor, M.J.; Garrido-Perez, M.C.; Acevedo, A.; Quiroga, J.M. Ozonation of Ibuprofen: A Degradation and Toxicity Study. Sci. Total Environ. 2014, 466-467, 957-964. [CrossRef] [PubMed]

21. Hartmann, J.; Bartels, P.; Mau, U.; Witter, M.; Tümpling, W.V.; Hofmann, J.; Nietzschmann, E. Degradation of the Drug Diclofenac in Water by Sonolysis in Presence of Catalysts. Chemosphere 2008, 70, 453-461. [CrossRef] [PubMed]

22. Langenhoff, A.; Inderfurth, N.; Veuskens, T.; Schraa, G.; Blokland, M.; Kujawa-Roeleveld, K.; Rijnaarts, H. Microbial Removal of the Pharmaceutical Compounds Ibuprofen and Diclofenac from Wastewater. BioMed Res. Int. 2013, 2013, 1-9. [CrossRef]

23. Gómez-Espinosa, R.M.; Arizmendi-Cotero, D. Use of Membrane for Removal of Nonsteroidal Anti-Inflammatory Drugs. In Non-Steroidal Anti-Inflammatory Drugs in Water: Emerging Contaminants and Ecological Impact; Gómez-Oliván, L.M., Ed.; The Handbook of Environmental Chemistry; Springer International Publishing: Cham, Switzerland, 2020; pp. 261-276. [CrossRef]

24. Ibrahem, A.K.; Abdel Moghny, T.; Mustafa, Y.M.; Maysour, N.E.; Mohamed Saad El Din El Dars, F.; Farouk Hassan, R. Degradation of Trichloroethylene Contaminated Soil by Zero-Valent Iron Nanoparticles. ISRN Soil Sci. 2012, 2012, e270830. [CrossRef] 
25. Kim, H.; Hong, H.-J.; Jung, J.; Kim, S.-H.; Yang, J.-W. Degradation of Trichloroethylene (TCE) by Nanoscale Zero-Valent Iron (NZVI) Immobilized in Alginate Bead. J. Hazard. Mater. 2010, 176, 1038-1043. [CrossRef]

26. Zhang, H.; Zhang, B.; Liu, B. Integrated Nanozero Valent Iron and Biosurfactant-Aided Remediation of PCB-Contaminated Soil. Appl. Environ. Soil Sci. 2016, 2016, e5390808. [CrossRef]

27. Mystrioti, C.; Sparis, D.; Papasiopi, N.; Xenidis, A.; Dermatas, D.; Chrysochoou, M. Assessment of Polyphenol Coated Nano Zero Valent Iron for Hexavalent Chromium Removal from Contaminated Waters. Bull. Environ. Contam. Toxicol. 2015, $94,302-307$. [CrossRef]

28. Ali, I.; ALOthman, Z.A.; Al-Warthan, A. Molecular Uptake of Congo Red Dye from Water on Iron Composite Nano Particles. J. Mol. Liq. 2016, 224, 171-176. [CrossRef]

29. Hanay, Ö.; Türk, H. An overview on usage of nanoscale zero valent iron for pharmaceuticals elimination. Eskişeh. Tek. Üniv. Bilim Ve Teknol. Derg. B Teor. Bilim. 2019, 7, 222-239. [CrossRef]

30. Lu, H.-J.; Wang, J.-K.; Ferguson, S.; Wang, T.; Bao, Y.; Hao, H. Mechanism, Synthesis and Modification of Nano Zerovalent Iron in Water Treatment. Nanoscale 2016, 8, 9962-9975. [CrossRef]

31. Li, X.; Elliott, D.W.; Zhang, W. Zero-Valent Iron Nanoparticles for Abatement of Environmental Pollutants: Materials and Engineering Aspects. Crit. Rev. Solid State Mater. Sci. 2006, 31, 111-122. [CrossRef]

32. Martin, J.E.; Herzing, A.A.; Yan, W.; Li, X.; Koel, B.E.; Kiely, C.J.; Zhang, W. Determination of the Oxide Layer Thickness in Core-Shell Zerovalent Iron Nanoparticles. Langmuir 2008, 24, 4329-4334. [CrossRef] [PubMed]

33. O'Carroll, D.; Sleep, B.; Krol, M.; Boparai, H.; Kocur, C. Nanoscale Zero Valent Iron and Bimetallic Particles for Contaminated Site Remediation. Adv. Water Resour. 2013, 51, 104-122. [CrossRef]

34. Girit, B.; Dursun, D.; Olmez-Hanci, T.; Arslan-Alaton, I. Treatment of Aqueous Bisphenol A Using Nano-Sized Zero-Valent Iron in the Presence of Hydrogen Peroxide and Persulfate Oxidants. Water Sci. Technol. J. Int. Assoc. Water Pollut. Res. 2015, 71, 1859-1868. [CrossRef]

35. Xi, Y.; Sun, Z.; Hreid, T.; Ayoko, G.A.; Frost, R.L. Bisphenol A Degradation Enhanced by Air Bubbles via Advanced Oxidation Using in Situ Generated Ferrous Ions from Nano Zero-Valent Iron/Palygorskite Composite Materials. Chem. Eng. J. 2014, 247, 66-74. [CrossRef]

36. Ghauch, A.; Tuqan, A.; Assi, H.A. Antibiotic Removal from Water: Elimination of Amoxicillin and Ampicillin by Microscale and Nanoscale Iron Particles. Environ. Pollut. 2009, 157, 1626-1635. [CrossRef]

37. Fang, Z.; Chen, J.; Qiu, X.; Qiu, X.; Cheng, W.; Zhu, L. Effective Removal of Antibiotic Metronidazole from Water by Nanoscale Zero-Valent Iron Particles. Desalination 2011, 268, 60-67. [CrossRef]

38. Chen, X.-L.; Li, F.; Xie, X.J.; Li, Z.; Chen, L. Nanoscale Zero-Valent Iron and Chitosan Functionalized Eichhornia Crassipes Biochar for Efficient Hexavalent Chromium Removal. Int. J. Environ. Res. Public Health 2019, 16, 3046. [CrossRef]

39. Yuzhou, Z.; Wang, T.; Zhi, D.; Binglin, G.; Zhou, Y.; Nie, J.; Huang, A.; Yang, Y.; Huang, H.; Luo, L. Applications of Nanoscale Zero-Valent Iron and Its Composites to the Removal of Antibiotics: A Review. J. Mater. Sci. 2019, 54, 12171-12188. [CrossRef]

40. Maschal Tarekegn, M.; Mekonnen Hiruy, A.; Hussen Dekebo, A. Nano Zero Valent Iron (NZVI) Particles for the Removal of Heavy Metals (Cd 2+, Cu 2+ and Pb 2+ ) from Aqueous Solutions. RSC Adv. 2021, 11, 18539-18551. [CrossRef]

41. Machado, S.; Stawiński, W.; Slonina, P.; Pinto, A.R.; Grosso, J.P.; Nouws, H.P.A.; Albergaria, J.T.; Delerue-Matos, C. Application of Green Zero-Valent Iron Nanoparticles to the Remediation of Soils Contaminated with Ibuprofen. Sci. Total Environ. 2013, 461-462, 323-329. [CrossRef]

42. Shao, Y.; Zhao, P.; Yue, Q.; Wu, Y.; Gao, B.; Kong, W. Preparation of Wheat Straw-Supported Nanoscale Zero-Valent Iron and Its Removal Performance on Ciprofloxacin. Ecotoxicol. Environ. Saf. 2018, 158, 100-107. [CrossRef]

43. Bao, T.; Damtie, M.M.; Hosseinzadeh, A.; Wei, W.; Jin, J.; Phong Vo, H.N.; Ye, J.S.; Liu, Y.; Wang, X.F.; Yu, Z.M.; et al. BentoniteSupported Nano Zero-Valent Iron Composite as a Green Catalyst for Bisphenol A Degradation: Preparation, Performance, and Mechanism of Action. J. Environ. Manag. 2020, 260, 110105. [CrossRef]

44. Wu, J.; Wang, B.; Cagnetta, G.; Huang, J.; Wang, Y.; Deng, S.; Yu, G. Nanoscale Zero Valent Iron-Activated Persulfate Coupled with Fenton Oxidation Process for Typical Pharmaceuticals and Personal Care Products Degradation. Sep. Purif. Technol. 2020, 239, 116534. [CrossRef]

45. Babuponnusami, A.; Muthukumar, K. Removal of Phenol by Heterogenous Photo Electro Fenton-like Process Using Nano-Zero Valent Iron. Sep. Purif. Technol. 2012, 98, 130-135. [CrossRef]

46. Midik Ertosun, F.; Cellat, K.; Eren, O.; Gül, Ş.; Kuşvuran, E.; Şen, F. Comparison of Nanoscale Zero-Valent Iron, Fenton, and Photo-Fenton Processes for Degradation of Pesticide 2,4-Dichlorophenoxyacetic Acid in Aqueous Solution. SN Appl. Sci. 2019, 1, 1491. [CrossRef]

47. Machado, S.; Pinto, S.L.; Grosso, J.P.; Nouws, H.P.A.; Albergaria, J.; Delerue-Matos, C. Green Production of Zero-Valent Iron Nanoparticles Using Tree Leaf Extracts. Sci. Total Environ. 2013, 445-446C, 1-8. [CrossRef]

48. Voros, V.; Drioli, E.; Fonte, C.; Szekely, G. Process Intensification via Continuous and Simultaneous Isolation of Antioxidants: An Upcycling Approach for Olive Leaf Waste. ACS Sustain. Chem. Eng. 2019, 7, 18444-18452. [CrossRef]

49. Toli, A.; Varouxaki, A.; Mystrioti, C.; Xenidis, A.; Papassiopi, N. Green Synthesis of Resin Supported Nanoiron and Evaluation of Efficiency for the Remediation of $\mathrm{Cr}(\mathrm{VI})$ Contaminated Groundwater by Batch Tests. Bull. Environ. Contam. Toxicol. 2018, 101, 711-717. [CrossRef] 
50. Tian, X.; Gao, R.; Wang, Y.; He, Y.; Hussain, S.; Heinlein, J.; Tian, J.; Pfefferle, L.D.; Tang, X.; Tang, Y. Layer-by-Layer Assembled Magnetic Molecularly Imprinted Nanoparticles for the Highly Specific Recovery of Luteolin from Honeysuckle Leaves. Green Chem. 2021, 23, 3623-3632. [CrossRef]

51. Stefaniuk, M.; Oleszczuk, P.; Ok, Y.S. Review on Nano Zerovalent Iron (NZVI): From Synthesis to Environmental Applications. Chem. Eng. J. 2016, 287, 618-632. [CrossRef]

52. Crane, R.A.; Scott, T.B. Nanoscale Zero-Valent Iron: Future Prospects for an Emerging Water Treatment Technology. J. Hazard. Mater. 2012, 211-212, 112-125. [CrossRef]

53. Livingston, A.; Trout, B.L.; Horvath, I.T.; Johnson, M.D.; Vaccaro, L.; Coronas, J.; Babbitt, C.W.; Zhang, X.; Pradeep, T.; Drioli, E.; et al. Challenges and Directions for Green Chemical Engineering-Role of Nanoscale Materials. In Sustainable Nanoscale Engineering; Szekely, G., Livingston, A., Eds.; Elsevier: Amsterdam, The Netherlands, 2020; Chapter 1; pp. 1-18. [CrossRef]

54. Jahan, S.; Yusoff, I.B.; Alias, Y.B.; Bakar, A.F.B.A. Reviews of the Toxicity Behavior of Five Potential Engineered Nanomaterials (ENMs) into the Aquatic Ecosystem. Toxicol. Rep. 2017, 4, 211-220. [CrossRef] [PubMed]

55. Yoon, H.; Pangging, M.; Jang, M.-H.; Hwang, Y.S.; Chang, Y.-S. Impact of Surface Modification on the Toxicity of Zerovalent Iron Nanoparticles in Aquatic and Terrestrial Organisms. Ecotoxicol. Environ. Saf. 2018, 163, 436-443. [CrossRef]

56. Wang, S.; Zhao, M.; Zhou, M.; Li, Y.C.; Wang, J.; Gao, B.; Sato, S.; Feng, K.; Yin, W.; Igalavithana, A.D.; et al. Biochar-Supported NZVI (NZVI/BC) for Contaminant Removal from Soil and Water: A Critical Review. J. Hazard. Mater. 2019, 373, 820-834. [CrossRef]

57. Lv, X.; Xu, J.; Jiang, G.; Xu, X. Removal of Chromium(VI) from Wastewater by Nanoscale Zero-Valent Iron Particles Supported on Multiwalled Carbon Nanotubes. Chemosphere 2011, 85, 1204-1209. [CrossRef]

58. Li, Z.; Wang, L.; Meng, J.; Liu, X.; Xu, J.; Wang, F.; Brookes, P. Zeolite-Supported Nanoscale Zero-Valent Iron: New Findings on Simultaneous Adsorption of $\mathrm{Cd}(\mathrm{II}), \mathrm{Pb}(\mathrm{II})$, and $\mathrm{As}(\mathrm{III})$ in Aqueous Solution and Soil. J. Hazard. Mater. 2018, 344, 1-11. [CrossRef]

59. Orbulet, O.; Modrogan, C.; Bobirica, C.; Bobirica, L.; Dancila, A.; Orbeci, C. Anion exchange resin-supported NZVI permeable reactive barriers for removal of nitrates from groundwater. Int. Symp. Environ. Ind. 2020, 14-15. [CrossRef]

60. PubChem. Ibuprofen. Available online: https://pubchem.ncbi.nlm.nih.gov/compound/3672 (accessed on 1 August 2021).

61. PubChem. Diclofenac. Available online: https://pubchem.ncbi.nlm.nih.gov/compound/3033 (accessed on 1 August 2021).

62. PubChem. Ketoprofen. Available online: https://pubchem.ncbi.nlm.nih.gov/compound/3825 (accessed on 1 August 2021).

63. PubChem. Naproxen. Available online: https://pubchem.ncbi.nlm.nih.gov/compound/156391 (accessed on 1 August 2021).

64. Koumaki, E.; Mamais, D.; Noutsopoulos, C. Assessment of the Environmental Fate of Endocrine Disrupting Chemicals in Rivers. Sci. Total Environ. 2018, 628-629, 947-958. [CrossRef] [PubMed]

65. Samaras, V.G.; Thomaidis, N.S.; Stasinakis, A.S.; Lekkas, T.D. An Analytical Method for the Simultaneous Trace Determination of Acidic Pharmaceuticals and Phenolic Endocrine Disrupting Chemicals in Wastewater and Sewage Sludge by Gas ChromatographyMass Spectrometry. Anal. Bioanal. Chem. 2011, 399, 2549-2561. [CrossRef]

66. Tran, T. Standard Methods for the Examination of Water and Wastewater, 23rd ed. Available online: https://engage.awwa.org/ PersonifyEbusiness/Store/Product-Details/productId/65266295 (accessed on 14 November 2021).

67. Toli, A.; Chalastara, K.; Mystrioti, C.; Xenidis, A.; Papassiopi, N. Incorporation of Zero Valent Iron Nanoparticles in the Matrix of Cationic Resin Beads for the Remediation of Cr(VI) Contaminated Waters. Environ. Pollut. 2016, 214, 419-429. [CrossRef]

68. Izadi, P.; Izadi, P.; Salem, R.; Papry, S.A.; Magdouli, S.; Pulicharla, R.; Brar, S.K. Non-Steroidal Anti-Inflammatory Drugs in the Environment: Where Were We and How Far We Have Come? Environ. Pollut. 2020, 267, 115370. [CrossRef]

69. Płuciennik-Koropczuk, E. Non-Steroid Anti-Infflamatory Drugs in Municipal Wastewater and Surface Waters/ Niesteroidowe Leki Przeciwzaplane W Ściekach Mieskich I Wodach Powierzchniowych. Civ. Environ. Eng. Rep. 2014, 14, 63-74. [CrossRef]

70. Xie, J.; Gu, X.; Tong, F.; Zhao, Y.; Tan, Y. Surface Complexation Modeling of Cr(VI) Adsorption at the Goethite-Water Interface. J. Colloid Interface Sci. 2015, 455, 55-62. [CrossRef]

71. Khazri, H.; Ghorbel-Abid, I.; Kalfat, R.; Trabelsi-Ayadi, M. Removal of Ibuprofen, Naproxen and Carbamazepine in Aqueous Solution onto Natural Clay: Equilibrium, Kinetics, and Thermodynamic Study. Appl. Water Sci. 2017, 7, 3031-3040. [CrossRef]

72. Van Tran, T.; Cam Nguyen, D.T.; Le, H.T.N.; Nguyen, O.T.K.; Nguyen, V.H.; Nguyen, T.T.; Bach, L.G.; Nguyen, T.D. A Hollow Mesoporous Carbon from Metal-Organic Framework for Robust Adsorbability of Ibuprofen Drug in Water. R. Soc. Open Sci. 2019, 6, 190058. [CrossRef]

73. Kerkhoff, C.M.; da Boit Martinello, K.; Franco, D.S.P.; Netto, M.S.; Georgin, J.; Foletto, E.L.; Piccilli, D.G.A.; Silva, L.F.O.; Dotto, G.L. Adsorption of Ketoprofen and Paracetamol and Treatment of a Synthetic Mixture by Novel Porous Carbon Derived from Butia Capitata Endocarp. J. Mol. Liq. 2021, 339, 117184. [CrossRef]

74. Su, Y.; Jassby, D.; Song, S.; Zhou, X.; Zhao, H.; Filip, J.; Petala, E.; Zhang, Y. Enhanced Oxidative and Adsorptive Removal of Diclofenac in Heterogeneous Fenton-like Reaction with Sulfide Modified Nanoscale Zerovalent Iron. Environ. Sci. Technol. 2018, 52, 6466-6475. [CrossRef]

75. Streit, A.F.M.; Collazzo, G.C.; Druzian, S.P.; Verdi, R.S.; Foletto, E.L.; Oliveira, L.F.S.; Dotto, G.L. Adsorption of Ibuprofen, Ketoprofen, and Paracetamol onto Activated Carbon Prepared from Effluent Treatment Plant Sludge of the Beverage Industry. Chemosphere 2021, 262, 128322. [CrossRef]

76. Dong, S.; Zhai, X.; Pi, R.; Wei, J.; Wang, Y.; Sun, X. Efficient Degradation of Naproxen by Persulfate Activated with Zero-Valent Iron: Performance, Kinetic and Degradation Pathways. Water Sci. Technol. 2020, 81, 2078-2091. [CrossRef] [PubMed] 
77. Zhou, N.; Zhou, N.; Liang, W.; Liang, W.; Dai, C.; Dai, C.; Duan, Y.; Duan, Y. Application of Zero-Valent Iron Nanoparticles for Diclofenac Removal. In Proceedings of the International Workshop on Environment and Geoscience; SCITEPRESS-Science and Technology Publications, Hangzhou, China, 15-17 June 2018; pp. 87-91. [CrossRef]

78. Yang, Y.; Xu, L.; Li, W.; Fan, W.; Song, S.; Yang, J. Adsorption and Degradation of Sulfadiazine over Nanoscale Zero-Valent Iron Encapsulated in Three-Dimensional Graphene Network through Oxygen-Driven Heterogeneous Fenton-like Reactions. Appl. Catal. B Environ. 2019, 259, 118057. [CrossRef]

79. Mo, P.; Fu, D.; Chen, P.; Zhang, Q.; Zheng, X.; Hao, J.; Zhuang, X.; Liu, H.; Liu, G.; Lv, W. Ionic Covalent Organic Frameworks for Non-Steroidal Anti-Inflammatory Drugs (NSAIDs) Removal from Aqueous Solution: Adsorption Performance and Mechanism. Sep. Purif. Technol. 2021, 278, 119238. [CrossRef]

80. Zhang, G.; Li, S.; Shuang, C.; Mu, Y.; Li, A.; Tan, L. The Effect of Incorporating Inorganic Materials into Quaternized Polyacrylic Polymer on Its Mechanical Strength and Adsorption Behaviour for Ibuprofen Removal. Sci. Rep. 2020, 10, 5188. [CrossRef] [PubMed]

81. Noutsopoulos, C.; Koumaki, E.; Mamais, D.; Nika, M.-C.; Bletsou, A.A.; Thomaidis, N.S. Removal of Endocrine Disruptors and Non-Steroidal Anti-Inflammatory Drugs through Wastewater Chlorination: The Effect of PH, Total Suspended Solids and Humic Acids and Identification of Degradation by-Products. Chemosphere 2015, 119, S109-S114. [CrossRef]

82. Soares, S.F.; Trindade, T.; Daniel-da-Silva, A.L. Enhanced Removal of Non-Steroidal Inflammatory Drugs from Water by Quaternary Chitosan-Based Magnetic Nanosorbents. Coatings 2021, 11, 964. [CrossRef]

83. Baccar, R.; Sarrà, M.; Bouzid, J.; Feki, M.; Blánquez, P. Removal of Pharmaceutical Compounds by Activated Carbon Prepared from Agricultural By-Product. Chem. Eng. J. 2012, s211-212, 310-317. [CrossRef]

84. ALOthman, Z.A.; Badjah, A.Y.; Alharbi, O.M.L.; Ali, I. Synthesis of Chitosan Composite Iron Nanoparticles for Removal of Diclofenac Sodium Drug Residue in Water. Int. J. Biol. Macromol. 2020, 159, 870-876. [CrossRef] [PubMed]

85. Sulaiman, S.M.; Al-Jabari, M.H. Enhanced Adsorptive Removal of Diclofenac Sodium from Aqueous Solution by BentoniteSupported Nanoscale Zero-Valent Iron. Arab. J. Basic Appl. Sci. 2021, 28, 51-63. [CrossRef]

86. Mahmoud, A.; EL-Tayieb, M.; Ahmed, N. Algorithms and Statistics for Municipal Wastewater Treatment Using Nano Zero Valent Iron (NZVI). J. Environ. Biotehnol. Res. 2018, 7, 30-44.

87. Liang, W.; Zhou, N.; Dai, C.; Duan, Y.; Tu, Y. Zero-Valent Iron Nanoparticles and Its Combined Process for Diclofenac Degradation under Various Experimental Conditions. Pol. J. Environ. Stud. 2021, 30, 1279-1288. [CrossRef]

88. Ali, I.; Alothman, Z.; Alwarthan, A. Synthesis of Composite Iron Nano Adsorbent and Removal of Ibuprofen Drug Residue from Water. J. Mol. Liq. 2016, 219, 858-864. [CrossRef]

89. Liu, Y.-J.; Lo, S.-L.; Liou, Y.-H.; Hu, C.-Y. Removal of Nonsteroidal Anti-Inflammatory Drugs (NSAIDs) by ElectrocoagulationFlotation with a Cationic Surfactant. Sep. Purif. Technol. 2015, 152, 148-154. [CrossRef]

90. Al-rimawi, F.; Daana, M.; Khamis, M.; Karaman, R.; Khoury, H.; Qurie, M. Removal of Selected Pharmaceuticals from Aqueous Solutions Using Natural Jordanian Zeolite. Arab. J. Sci. Eng. 2019, 44, 209-215. [CrossRef]

91. Gao, Y.; Zhang, J.; Zhou, J.; Li, C.; Gao, N.; Yin, D. Persulfate Activation by Nano Zero-Valent Iron for the Degradation of Metoprolol in Water: Influencing Factors, Degradation Pathways and Toxicity Analysis. RSC Adv. 2020, 10, 20991-20999. [CrossRef] 